\title{
Chapter 8 \\ Collagen Fabrication for the Cell-based Implants in Regenerative Medicine
}

\author{
Hwal (Matthew) SUH
}

Yonsei University, Seoul 120-752, Republic of Korea, hwal@yumc.yonsei.ac.kr

\begin{abstract}
Though transplantation of cells, tissue or organ has been regarded as an ideal approach, scarcity of donor is a practical barrier in clinics. Current progresses in cell engineering has opened a new era, providing tools for host-regeneration by implanting manipulated cells in forms of cell therapy, which includes delivery of single cells or multicellular structural support of hybridized cells, as a representative individualized treatment method. This chapter mainly concerns on the cellbased implant made of cells and collagen, the main structural protein in extracellular matrix in mammalian tissue, as it has been regarded as a promising method for manufacturing a biologically mimicked artificial tissues.
\end{abstract}

\subsection{Regenerative Medicine}

Regenerative medicine is to repair, replace and/or modify the disordered or damaged human body, either from a disease and/or an injury, via functional regeneration of the host cells, tissues and organs by placing appropriate cells of optimal quantity into the damaged body and maintaining the cellular functions that provide expected efficacy. Outcome of the regenerative medical treatment completely depends on the viability of delivered cells.

Embedding and planting, referred to as implantation, of devices made of biocompatible materials has been widely applied. Metals, ceramics, synthetic and natural polymers are the fundamental biomaterials that are convenient for processing and fabricating into various forms of tissue supporting structures. However, lack of their biological function is too far from the ideal goal for treatment.

From this perspective, transplantation which involves transferring procured cells, tissue or organ from a donor and planting into a recipient to replace the damaged lesion has been regarded as an ideal approach that provides biological restoration with recovery of physiological functions.

Nevertheless, the opportunity for selection of the completely perfect donor for a patient is critically limited in practice. The gene-homogeneity between the donor 
and recipient, mainly in human leukocyte antigen (HLA) types, is the first factor to avoid any post-operative complication oriented from the immune responses. Although autologous tissue is the most appropriate if damage or defect is not related to immune disease, applicable size and volume of donor site are extremely limited. Allogeneic tissue has been the second choice for transplantation since several immune-suppressive agents have been introduced, but these agents also lead to other immune-depressed diseases by breaking the natural immune homeostasis. Xenogeneic tissue and organ transplantation have been suggested by a number of researchers but longevity difference between human and donor animal is a great barrier that cannot be overcome at present.

An approach to treat gene-defect oriented congenital disease by delivering correct genes directly to a patient, known as gene therapy, has been introduced as an individualized treatment tool. Selected genes hybridized with a carrier vector are injected into a patient, and the vector may infect patient's cells and leave the selected genes within patient's cells. Then, the delivered genes may express its genetic characteristics necessary to cure the disease. However, the gene therapy bears several problems: (1) there is no perfect method to deliver genes into appropriate cells, (2) efficiency of gene expression varies, and (3) the gene delivering viral vector may induce unpredictable and unknown complications in body.

Another individualize treatment tool called cell therapy is planting therapeutic cells. Instead of transplanting tissue or organ, therapeutic cells are delivered in forms of either transplantation of natural cells or implantation of artificially manipulated cells. In addition, resource of applicable tissues from which therapeutic cells could be prepared is expanded. Conventional transplantation mainly consists of matured tissue or organ, but it is now possible to obtain therapeutic cells from any tissue at any growth stage, including embryonic blastocyst. Through in vitro gene modification of cells, it is possible to select only the cells which possess appropriate genes for treatment purposes from outside of the human body.

Theoretically, in case of autologous cell therapy, patient's cells are harvested through autopsy or procurement, and the treatment gene for correction is transfected into the cells. After culture, only the completely gene-transfected, healthy cells are collected, and the selected cells are further cultured to obtain abundant number of cells to deliver in forms of cell suspension for injection. As the whole procedure is performed in vitro environment, only perfectly modified therapeutic cells are selected. In case of allogeneic cell therapy, donor's HLA could be also replaced by the recipient's to escape from the post-operative immune rejection. Furthermore, risk of inducing uncontrollable oncogenesis oriented from the mutated cells is avoidable during the cell selecting procedure in vitro [1].

\subsection{The Cell-Based Implants}

To deliver the selected cells into the selected site in recipient's body, it is necessary to fabricate cell delivery vehicle with biomaterials that supply agents to maintain cell-viability and act as probes for piloting cells toward appropriate site. The 


\section{Cell Preparation for Implantation}

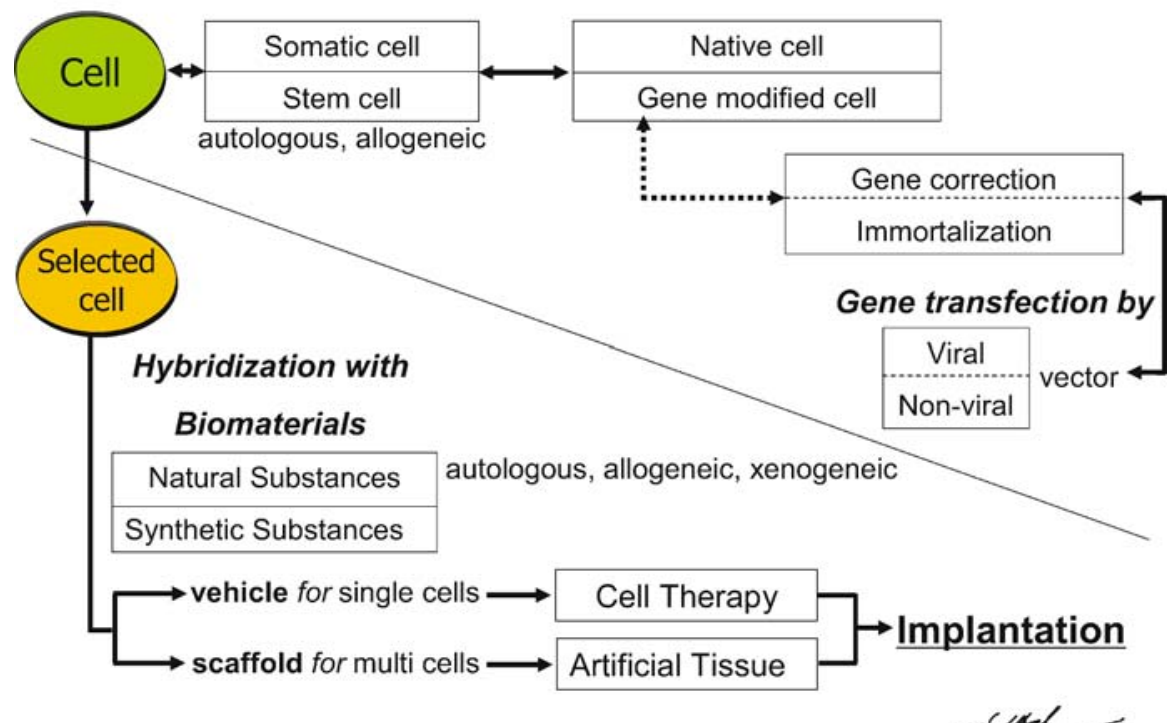

Fig. 8.1 Cell Preparation for Implantation

cell-based implant is defined as any implant in combination of cells and biomaterials which are intended to repair, modify and/or regenerate human body, through expected regulation and control of cellular functions and/or behaviors after implantation. The cell-based implant consists of artificially manipulated therapeutic cells hybridized with biomaterials in vitro. For cell therapy, each cell is individually hybridized with biomaterials, but in forms of tissue engineered implants, cells are hybridized with scaffold-biomaterials that act as structural support in the same way as the extracellular matrix in tissue does [2] (Fig. 8.1).

\subsection{Requirements of Materials for the Cell-Based Implants}

Substances applied to control biological events of cells may have biological risks. In manipulating cells, various kinds of substances functioning chemically at molecular level are used in cell-modifying procedures. Biological agents, such as enzymes in the nucleic acid recombination procedure, cytokines in cell differentiation and proliferation control, and peptides in cell culture media, are regarded as biologic substances, and they must not produce any biological hazard during the manipulation procedures.

In gene modification process, to avoid adverse reactions oriented from viral vectors, such as retrovirus, adenovirus and adeno-associate virus, non-viral vectors are designed to avoid biological risks and to manipulate easily. Capability of non-viral 
vectors is mainly dependent on endocytosis mechanism, but the extent of development in an artificial vector that provides efficient endosomal escape to deliver the gene finally into nucleus is still questionable at present.

Biocompatibility is the primary requirement for any material used in manufacturing implant. In the cell-based implants, the material hybridized with cells shall either biologically or mechanically be compatible with the neighboring cells at the delivered site. For cell therapy, each cell would be hybridized with nano-sized particles that have specific affinity to the treatment target site and self-driving ability. Particles shall be dissociated from the delivered cell after landing at the site and be completely excreted without accumulation in the recipient's body and any side effect. Size of a tissue cell is about $10 \times 10^{-5} \mathrm{~m}(=10 \mu \mathrm{m})$, a virus is $10 \times 10^{-7} \mathrm{~m}$ $(=100 \mathrm{~nm})$, diameter of a DNA is $10 \times 10^{-8} \mathrm{~m}(=10 \mathrm{~nm})$, diameter of a hydrogen atom is $10 \times 10^{-9} \mathrm{~m}(=1 \mathrm{~nm})$, and hybridizing substances are smaller than a $\mu \mathrm{m}$. However, there is no accurate tool to detect these extremely small, nano-scale particles that exist in living body for safety evaluation of a substance at present.

The cell-fabricating operator might be exposed to the substances during the whole manipulating procedure, and further investigation is necessary to avoid hazards. Otherwise, currently introduced biomaterials for cell encapsulation are designed to protect therapeutic cells from immune rejection while providing the excretion of biologics from the cell, and mostly to manufacture macromolecules with less difficulty to characterize [3].

\subsection{Biomaterials in the Cell-Hybridization}

In producing multicellular structural cell-based implants, so called tissue engineered implants, various biomaterials of either synthetic or natural substance are applied. Basically, conventionally available biomaterials can also be adopted as long as the permanent biocompatibility is approved.

Synthetic polymeric biomaterials are the representatives, and can be non-biodegradable or biodegradable after implantation. Non-biodegradable materials are usually intended for use in cell therapy where cell-encapsulation is required to provide and maintain optimal cellular function (e. g., alginate, liposome, etc.) by protecting the cells from host immune reaction, and/or for a tissue engineered implant, which requires the physiological load-bearing compliance (e. g., polyurethane scaffolds for blood vessels, tendons, ligaments, etc.) after implantation. They permanently remain at the planted place in recipient's body. Meanwhile, biodegradable materials are usually intended for use in implants which restore the histological structure and replace the cellular function of recipients. They are gradually degraded in recipient's body through hydrolysis or enzymatic function after implantation (e. g., poly L-lactic acid, poly glycolic acid, etc.).

In cases of using synthetic polymeric biomaterials, behavior of hybrid cells is mainly dependent on surface characteristics of material. Especially, the cellular events such as adhesion, differentiation, proliferation and migration on the non- 
biological synthetic biomaterial are important for maintaining viability of cells implanted in bio-inert materials. Furthermore, an increased regional acidity induced by dissolved acidic component through hydrolysis from the biodegradable materials demonstrates the limitation in mimicking natural biological environment with synthetic biomaterials.

Natural biomaterials are mainly composed of extracellular matrix (ECM) components (including structural components and biomolecules) originated from autologous, allogeneic and xenogeneic tissues of mammalians. Collagen, elastin, chondroitin-6-sulphate and hyaluronic acid are structural components.

Biomolecules, such as peptides, fibronectin, laminin, vitronectin and fibrin, and cytokines as growth factors and apoptosis signal promoters, are biologically active substances produced by nature. Non-mammalian substances such as silk fibroin, crab chitin and chitosan and agar are also included in this criteria. At this scope, it can be recognized that, although any xenogeneic cells are still not permitted, xenogeneic ECM components are permitted for the "trans-" or "im-"plantable biomaterials. For cell-based implants that utilize xenogeneic tissues or their derivatives as biomaterials, secure risk controls shall be applied on sourcing, collecting and handling xenogeneic ECM, on the validation of elimination and/or inactivation of adventitious agents, such as Transmissible Spongiform Encephalopathy (TSE) agents in case of using bovine tissue, in products.

Non-comparable biological superiority of natural ECM components are applied for improving biocompatibility of synthetic polymeric biomaterials as grafting materials onto the surface of material. Also, bioactive agents (including biologics, antibiotics, and antimicrobials) and/or synthetic drugs can be medicinal components in biomaterials, and they shall be assessed, in the context of their integration with the cell-based implant, according to pharmaceutical principles. This assessment shall consider the effects of medicinal components on product and vice versa. Furthermore, the medicinal components could be an additive to treat the recipient's disease [4].

\subsection{Characteristics of Collagen}

In mammalians, collagen comprises about $30 \%$ of total proteins and exists as a main structural component in ECM and supports anatomical morphology of every tissue and organ. Although more than 20 types of them are informed, type I collagen, which has a specific molecule of the super-coiled triple helical peptide chains, is the most abundant in body. In brief, each peptide chain is a specific left-handed helix of 100,000 molecular weight and consists of repeating "-Glycine-X-Y-" amino acid sequence. As the arginine-glycine-aspartic acid (RGD) sequence is a typical cell adhesive ligand, collagen demonstrates strong cell adhesion property.

3 left-handed helical peptide chains are integrated by intramolecular bindings of hydrogen bonds at glycines to glycines and hydroxyl bonds at hydroxyprolines to hydroxyprolines in each chain to form a right-handed triple helical collagen 


\section{Glycine}<smiles>NNC(=O)O</smiles>

\section{Proline}<smiles>O=C(O)C1CCCN1</smiles>

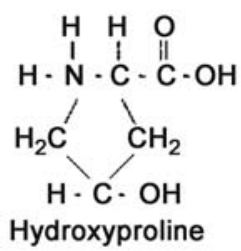

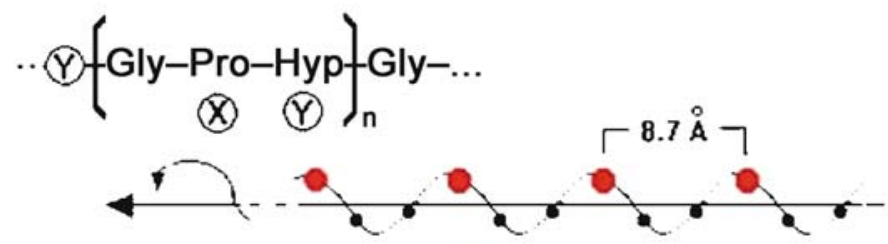

left-handed Single $\alpha$-chain

- imino acid

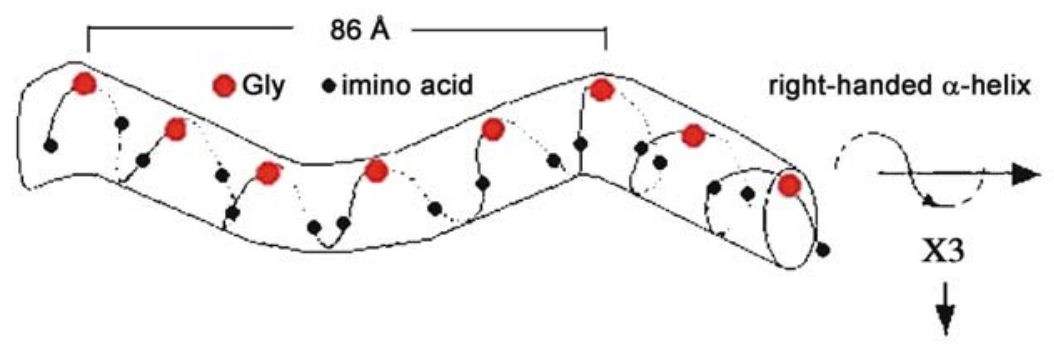

Tropocollagen

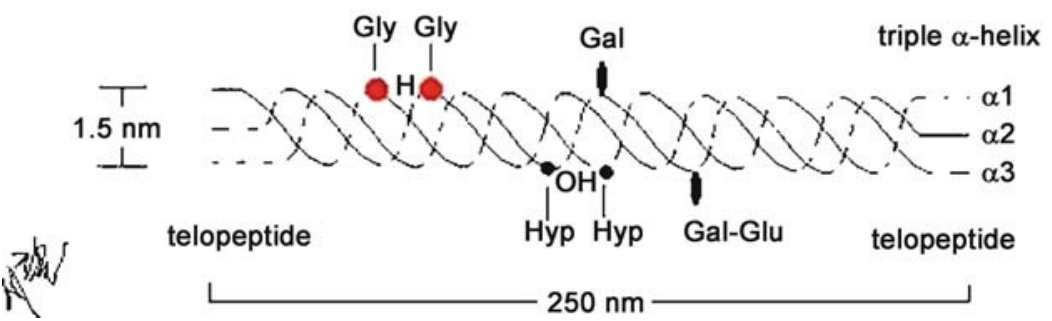

Fig. 8.2 Structure of Type I collagen molecule

molecule. In a chain, 1012 amino acids are involved in the formation of a molecule, and each free-end of a chain that is not integrated with the others, is made of $12-17$ amino acids and named as telopeptides. Each of these at the $\mathrm{C}$ - and $\mathrm{N}$ - terminals of molecule binds to another and forms a long linear chain. Collagen is easily denatured at temperature over $37^{\circ} \mathrm{C}$ through disintegration of the intermolecular bonds, and becomes gelatinized to form a randomly coiled chain with less viscosity than that of collagen. Once denatured, gelatin is amorphous and does recover the intermolecular bonds in nature and is more easily digested by metaloprotease than collagen. 
A type I collagen fibril consists of 5 collagen linear chains with strong intermolecular hydrogen bonds at lysine to lysine in each molecule.

In nature, $\varepsilon-\mathrm{NH}_{2}$ of lysines and hydroxylysines at the both extremities of telopeptide is converted to aldehydes by lysineoxidase, and the Schiff base formation by binding aldehyde with residual $\varepsilon-\mathrm{NH}_{2}$ or by aldol condensation between aldehyde to aldehyde occur. This strong molecular binding is called as the crosslinking and introduces strong mechanical characteristics to collagen to act as the structural matrix in tissue and provide organ morphology.

As hydrogen concentration of body fluid is $\mathrm{pH} 7.4$, collagen is regarded as a weak base substance, and is generally extracted from mammalian tissue.

Collagen is the hydrophobic protein and is generally insoluble in a neutral solution, but non-crosslinked collagen is soluble in the neutral base solution such as $\mathrm{NaCl}$ or $\mathrm{Na}_{2} \mathrm{HPO}_{4}$. On the other hand, weak acid such as $\mathrm{HCl}$, citric acid and acetate breaks the intermolecular Schiff base bonds and the acid soluble collagen molecules are extracted. After extracting acid soluble collagen, non-acid soluble remnants remain, and these are strongly crosslinked collagen fibrils. When additional process using pepsin that digests the linear intermolecular bonds at each telopeptide is performed, telopeptide-free collagen molecules, known as the atelocollagen, can be obtained from remaining collagen fibrils. Because telopeptide demonstrates individual gene-characteristics, these atelocollagen molecules are recognized as immune-free substance and are applicable to medical and pharmaceutical purposes.

High concentration of bases such as $\mathrm{NaCl}, \mathrm{Na}_{2} \mathrm{SO}_{4}, \mathrm{Na}_{2} \mathrm{HPO}_{4}$ aggregate the acid-soluble collagen molecules in solution, and this phenomenon is applied to produce collagen membranes, threads and hollow fibers. However, randomly reconstructed intramolecular and/or intermolecular bonds do not provide sufficient mechanical properties compared to natural collagen in tissue. Hence, in order to fabricate collagen with higher mechanical strength, re-crosslinking methods are introduced [5] (Fig. 8.2).

\subsection{Fabrication of Collagen}

Collagen has been regarded as the first candidate for hybridization with cells as it exists in every part of body as the main extracellular matrix component. Although implantation of xenogeneic cells is not practically permitted, immunefree atelocollagen is generally extracted from mammalians for medical use. Bovine is the most popular resource provided if cows are grown at the officially recognized region that is free from TSE.

As atelocollagen has no telopeptides that integrate with other atelocollagen molecules, basic technology to produce intramolecular and intermolecular bonds for construction of the extracellular matrix with adequate mechanical properties required by tissue where the artificial cell-based implant is delivered is the recrosslinking method using chemical reagents or physical dynamics.

Most common chemical reagent adopted for this process is glutaraldehyde that introduces stable covalent $\mathrm{NH}_{2}$ to $\mathrm{NH}_{2}$ bindings between the molecules. As amine 
to amine (NH-NH) bonding exists in every amino acid in molecules, the chemically crosslinked collagen demonstrates high strength, but irregular patterns of the crosslinked fibers and protracted resorption are general disadvantages. Furthermore, in case of using glutaraldehyde, complications due to residual aldehydes often conduct calcification that directly leads to the loss of mechanical strength. To overcome these disadvantages, 1-ethyl-3(3-dimethylaminopropyl) carbodiimide (EDC), which introduces $\mathrm{NH}_{2}$ to $\mathrm{COOH}$ covalent bonding and has no toxicity, has been applied to the procedure.

To avoid any disadvantage arising from the use chemical reagents, cross-linking by physical method is employed. Irradiating with gamma or ultraviolet rays produces radicals in the form of unpaired electrons in the nuclei of aromatic residues

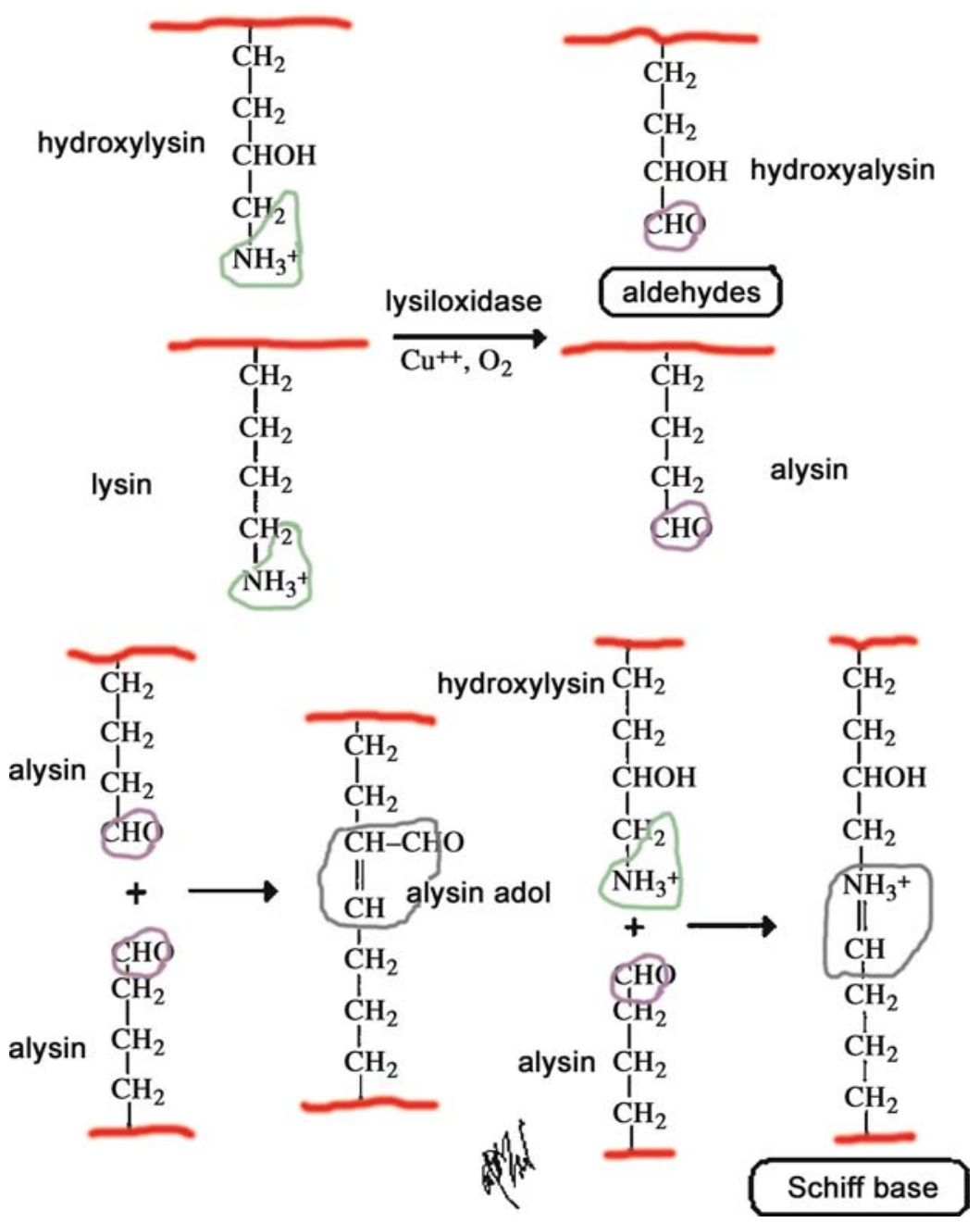

Fig. 8.3 Crosslinking of collagen molecule occurs by Schiff base formation in nature 
such as those in tyrosine and phenylalanine, and binding of these radicals results in the collagen cross-linking through random $\mathrm{NH}_{2}$ to $\mathrm{COOH}$ bonding. Even though the physical method is safe as it does not involve the use of chemicals, stability of the crosslink is less than that of chemically induced crosslink.

Collagen can be fabricated into various forms of gel, fiber, membrane with or without pores, and it can even be grafted onto the non-viable metal, ceramic and synthetic biomaterials to introduce biological layer on surface.

Atelocollagen gel is easily prepared by dispersing in weak acidic solutions. In general, collagen is dispersed in a weak acid solution of $\mathrm{pH}$ 6-6.5 and finally adjusted to required $\mathrm{pH}$ by adding base for medical purpose. Additive substance to

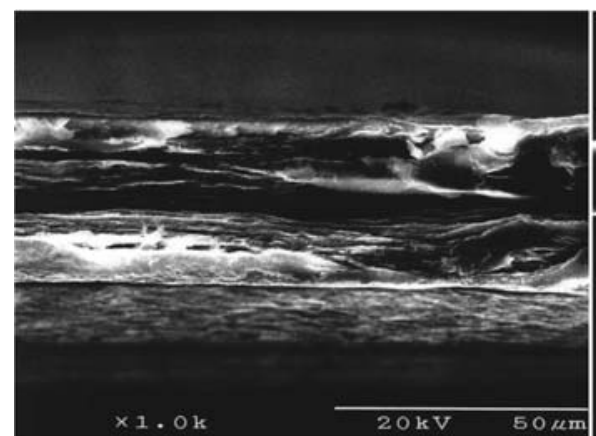

(a)

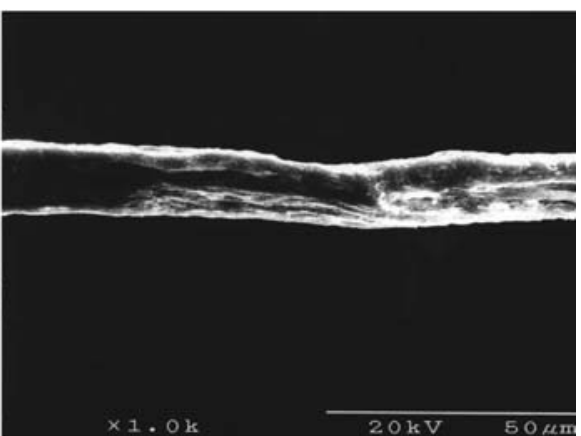

(b)

Fig. 8.4 Two hours of UV ray (wave length $245 \mathrm{~nm}$ ) irradiation cross-linked collagen matrix. $\mathbf{a}$ before, and $\mathbf{b}$ after irradiation

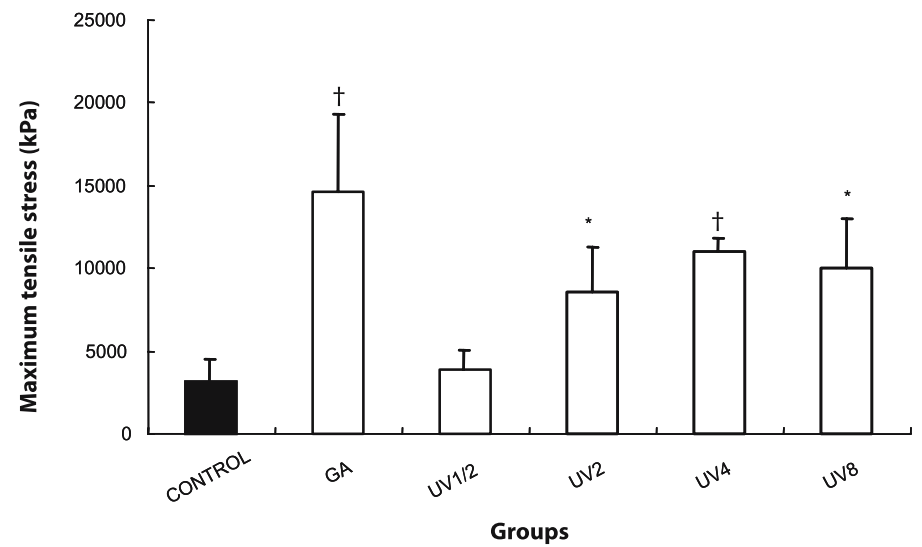

Fig. 8.5 Ultimate tensile stress of dense membrane in relation to UV irradiation time. Each value represents the mean $\pm \mathrm{SD}$ in five samples, ${ }^{*}$ and $\uparrow:$ significantly different compared to the control non-treated group for each type of membrane, ${ }^{*}: p<0.05$ and $\dagger: p<0.01$. CONTROL : nontreated group, UV1/2: UV-irradiated group for 30 mins, UV2: UV-irradiated group for 2 hours, UV4: UV-irradiated group for 4 hours, UV8: UV-irradiated group for 8 hours, GA: $0.625 \%$ glutaraldehyde pretreated group for 24 hours ( $Y$-axis: Maximum tensile stress $(\mathrm{kPa}))$ 
provide and/or control the biological function of the collagen can be introduced at this stage utilizing the high viscosity property.

Biochemical property of collagen molecule can be modified by varying the surface electric charge by altering the molecular side chain which leads to the adjustment of hydrophilicity-hydrophobicity balance. Succinylization of amines (NH$\left.\mathrm{CO}\left(\mathrm{CH}_{2}\right)_{2}-\mathrm{COOH}\right)$ by using anhydrate succinyl acid provides abundant $(-)$ charges, and the succinylated collagen becomes soluble in neutral solution, which finally results in translucent viscous collagen gel with hydrophilicity. Meanwhile esterization $\left(-\mathrm{COOCH}_{3}\right)$ of carboxyl group by methanol produces abundant $(+)$ charges on the collagen and provides a favorable hydrophobic niche for protein adhesion.

Atelocollagen gel is fabricated into fiber form by using an electro spinning. For example, a collagen solution dissolved in 1,1,1,3,3,3-hexafluoro-2-propanol (HFP) having concentration over $5 \%$ is useful to produce a diameter controlled nanofiber by passing it through a diameter adjustable nozzle under the condition of a high voltage at $25 \mathrm{kV}$, flow velocity at $2.5 \mathrm{~m} / \mathrm{h}$, metal collector of $2 \mathrm{~cm}$ width with rotating speed at $300 \mathrm{rpm}$, and distance between the metal collector and spinner of $15 \mathrm{~cm}$, and finally removing organic solute for 48 hours by drying in a vacuum chamber. The produced nanofiber is crosslinked by either EDC or UV irradiation later in order to reinforce the fiber strength, and demonstrates the typical triple helical structure of collagen molecule.

Freeze-drying the gel in vacuum condition is a simple procedure for fabrication of a porous membrane, as lower concentration and higher freezing temperature leads to smaller and bigger pores [6-10], (Figs. 8.3-8.8).
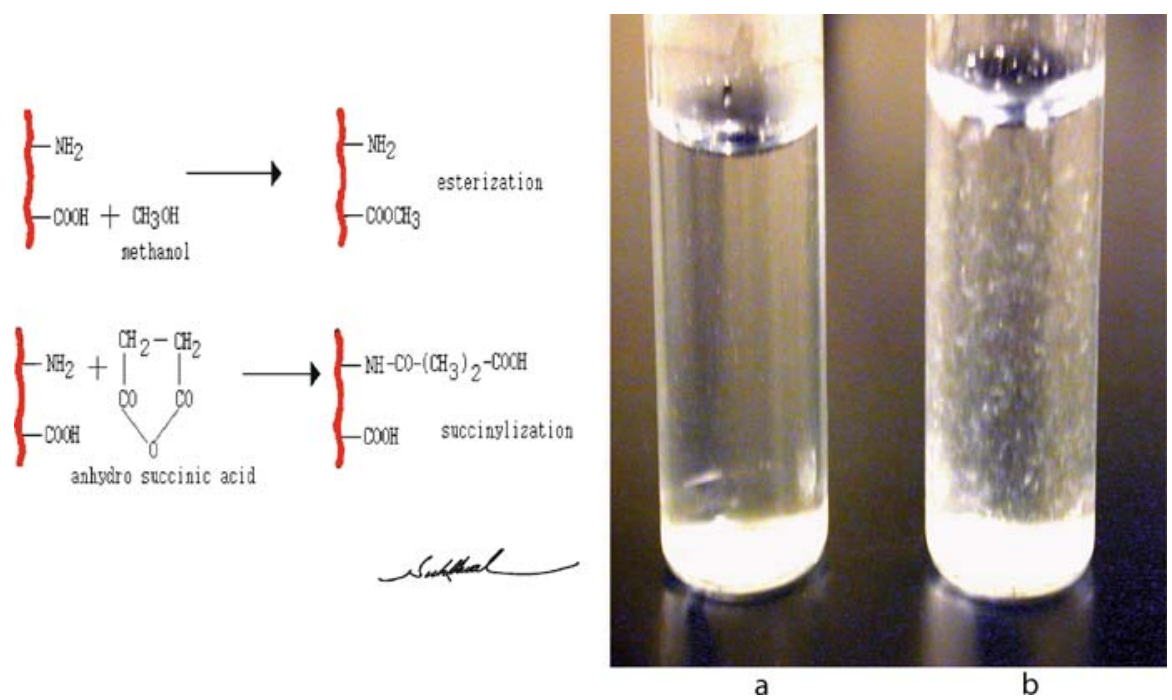

Fig. 8.6 Modification of collagen molecule to increase hydrophobicity by esterization or hydrophilicity by succinylation. Succinylated collagen (a) demonstrates higher solubility than normal collagen gel (b) in distilled water with hydrophilicity 


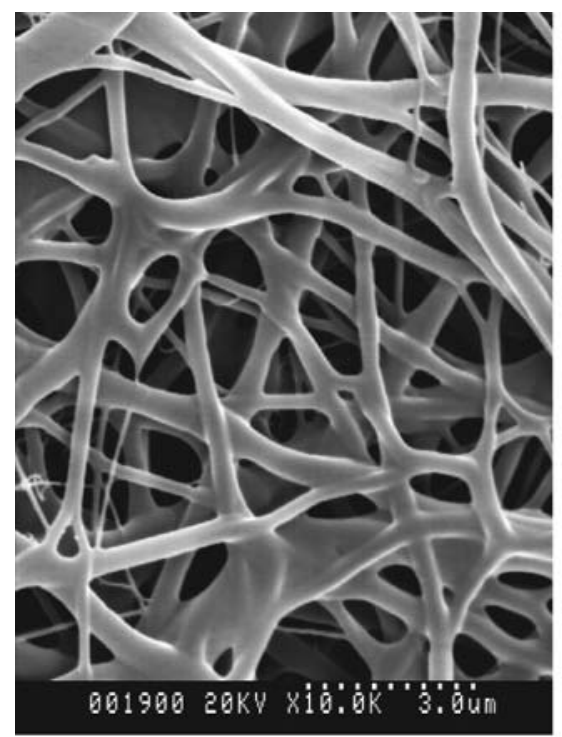

a

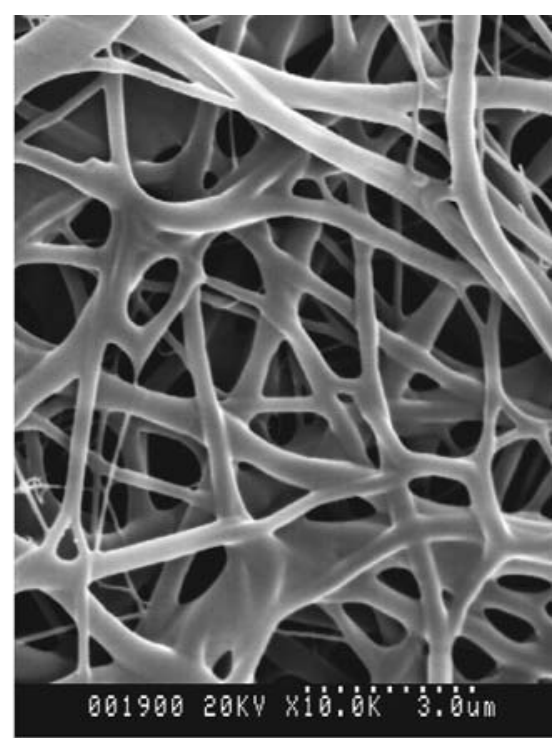

b

Fig. 8.7 A scanning electron microccopic surface view of an electrospun collagen nanofibrous membrane crosslinked by 1-ethyl-(3-3-dimethylaminopropyl) acrbodiimide hydrochloride (EDC). Crosslinking increased diameter of the nanofibers. a before crosslinking, $d: 448 \mathrm{~nm}$, b after crosslinking, $d: 618 \mathrm{~nm}$

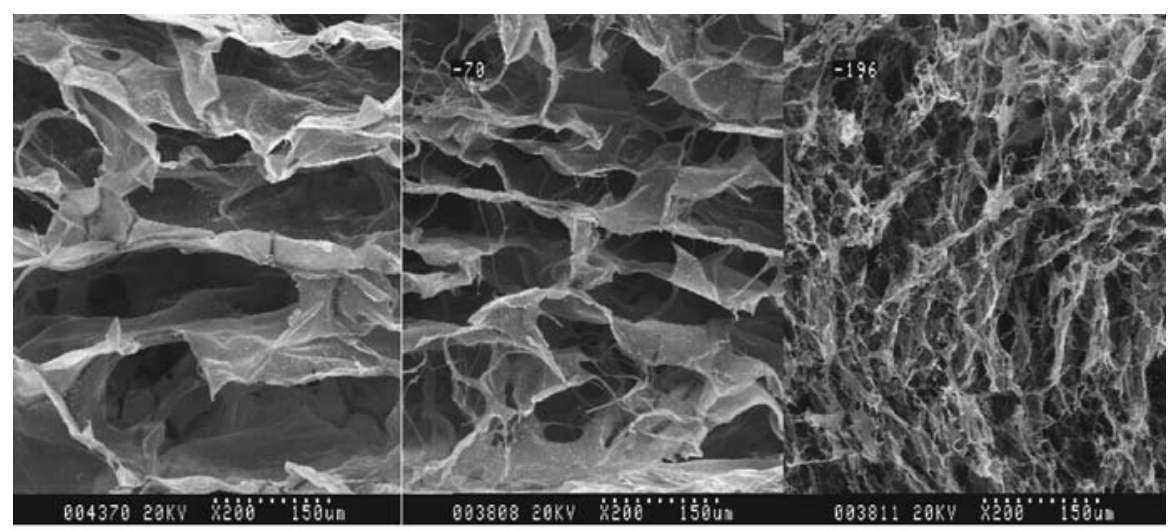

a

b

C

Fig. 8.8 Morphological observation of typeI atelocollagen porous membrane: a freezing dry at $-20^{\circ} \mathrm{C}$, b freezing dry at $-70{ }^{\circ} \mathrm{C}$, c freezing dry at $-196^{\circ} \mathrm{C}$. The lower temperature produces higher porosity 


\subsection{Collagen in the Cell-based Implants}

Collagen contains much of the cell adhesive RGD sequences in molecule, thus has cell conductive characteristics and is applied either in the independent form, in form of hybridization with biofunctional agents and cells, or, occasionally, in form of copolymer by introduction of synthetic polymers which is mainly aimed to enforce mechanical property.

\subsubsection{Skin Regeneration}

Collagen gel is usually applied to cell culture. A cell culture plate whose bottom surface is coated by collagen gel and dried makes it possible for suspended cells to produce a monolayered cell cluster by attaching them to the coated collagen layer. This technique is directly applied to produce skin wound dressing membranes.

Exposure of dermis to the open air, the grade 3 skin defect, in which the basal epithelial layer that prevents direct contact of inner body to the outer bodily environment and supports epithelium as the bed for keratinocytes is destroyed from burn, and sore spots induced by diabetes mellitus or accident are critical emergency in clinics. They evolve the direct contamination of dermis which usually progresses toward fatal septicemia or skin necrosis. The conventional treatment procedure mainly consists of complete irrigation and debridement of the wound, topical administration of broad spectrum antibacterial and antifungal agents, covering the wound by oily ointment to protect it from air contact, painful daily dressing change, and observation of the auto-regeneration of wound by proliferation of both dermal fibroblasts and epithelial keratinocytes and basement membrane reconstruction. Promoting proliferation of these skin cells with protection from air contact until complete healing is the key technology, and collagen membrane has been applied for this. For example, freeze dried atelocollagen in vacuum forms a membrane with random pores, and the pore size into which the cells may proliferate is controlled by the gel concentration and temperature at which it is frozen. Freeze dried collagen gel of 1,2 , and $5 \%$ in concentration at $-20,-40$, and $-80^{\circ} \mathrm{C}$ for $1 / 2,1,2$, and 4 hours demonstrated that higher concentration produced less and smaller sized pores. Also, the lower temperature and prolonged freezing time decreased viscosity. To produce a collagen membrane with optimal pore size of over $120 \mu \mathrm{m}$ which permits penetration and proliferation of dermal fibroblast proliferation, the $2 \%$ collagen gel freeze dried at $-40{ }^{\circ} \mathrm{C}$ for 2 hours and crosslinked by EDC or UV irradiation for 2 hours was found to be recommendable to use as a dermal cell conductive membrane that provides the appropriate viscosity for initial anchorage, and any inflammatory exudate escapes through pores.

A collagen bi-layered membrane is applied to skin in forms of either wound dressing or extracellular structural supporting matrix for artificial skin. Laminin, which is a cell adhesive protein and a main component of the basement membrane 
between dermis and epithelium, is mixed with $2 \%$ collagen gel. A porous collagenlaminin membrane is fabricated and freeze-dried as previously described and additional $4 \%$ collagen gel is coated on the porous membrane and crosslinking is promoted by EDC treatment or UV irradiation. Through this procedure, a bi-layered collagen matrix that consists of dense collagen layer overlaid on the prefabricated porous collagen-laminin membrane was produced. In use as a wound dressing, the upper dense layer prohibits direct wound contact with the open air and plays a role as a bed for keratinocyte proliferation, while the porous layer conducts dermal fibroblast proliferation. Thus, the painful daily dressing change becomes unnecessary. Antibacterial agents encapsulated by hyaluronic acid can be incorporated into the collagen gel and the drug may be released from the collagen membrane to avoid periodic topical drug application.

Fabrication of the bi-layered collagen membrane is the basic technology applicable to manufacture of artificial skin. In the 1980s, Bell introduced a method in

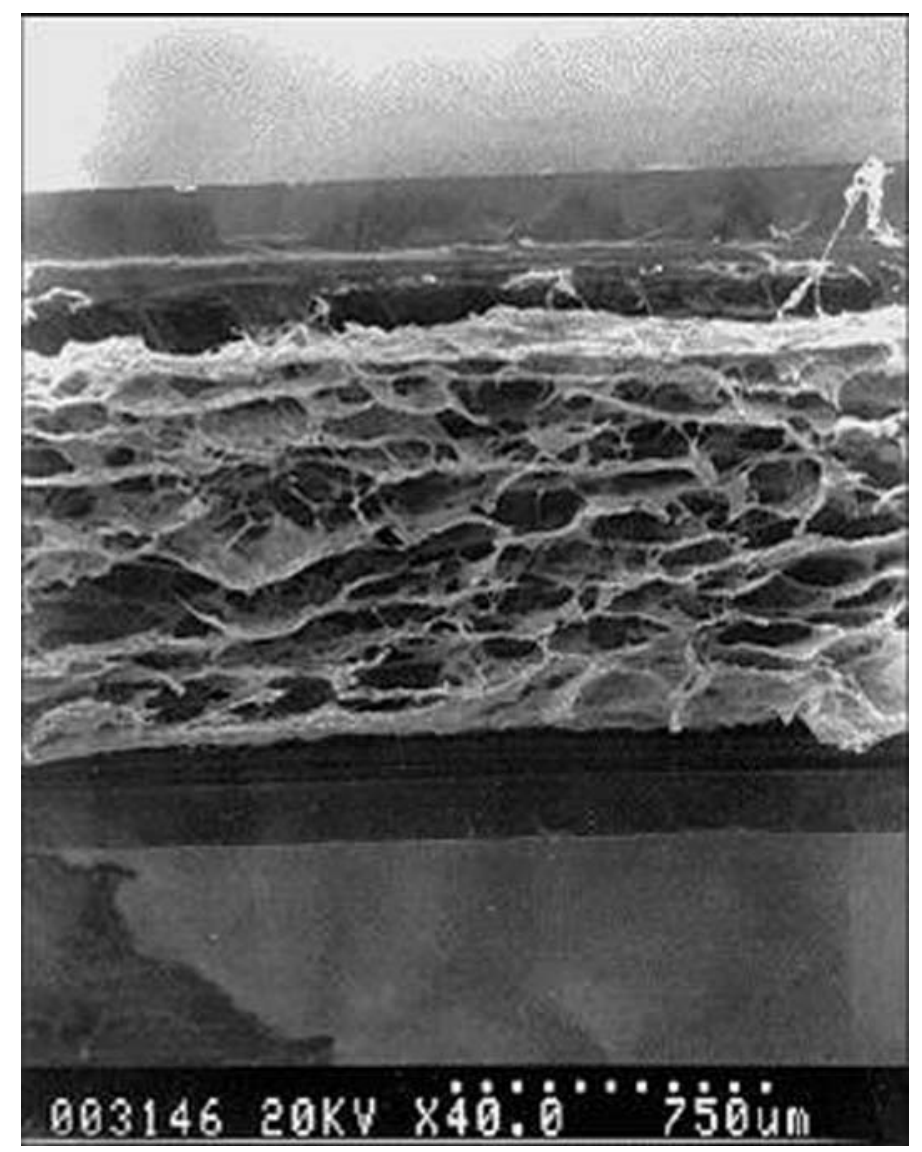

Fig. 8.9 Collagen-Laminin hybridized porous membrane for dermis 
which dermal fibroblasts and collagen gel mixture were cultured at $37^{\circ} \mathrm{C}$, and when the cells were confluent in the gradually shrinked gel, the collagen-fibroblast composite is produced. Keratinocytes were overlaid on the composite to mimic anatomy of the dermal cellular structure, but it required about 20 days for the manufacture to be completed and it was therefore not applicable to patients with grade 3 skin wound. On the other hand, Green introduced an advanced method in which dermal fibroblasts were cultured to form monolayer on a collagen coated culture plate and then keratinocyte was directly co-cultured on the fibroblast monolayer in a media

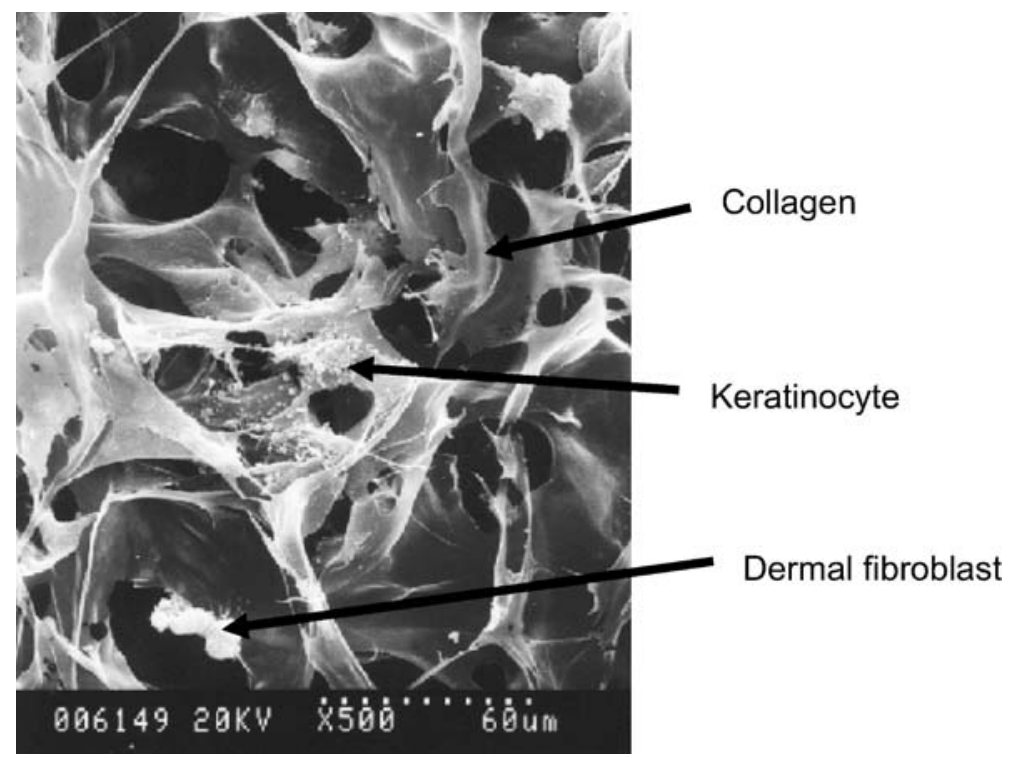

Fig. 8.10 Cells attached onto the porous collagen matrix
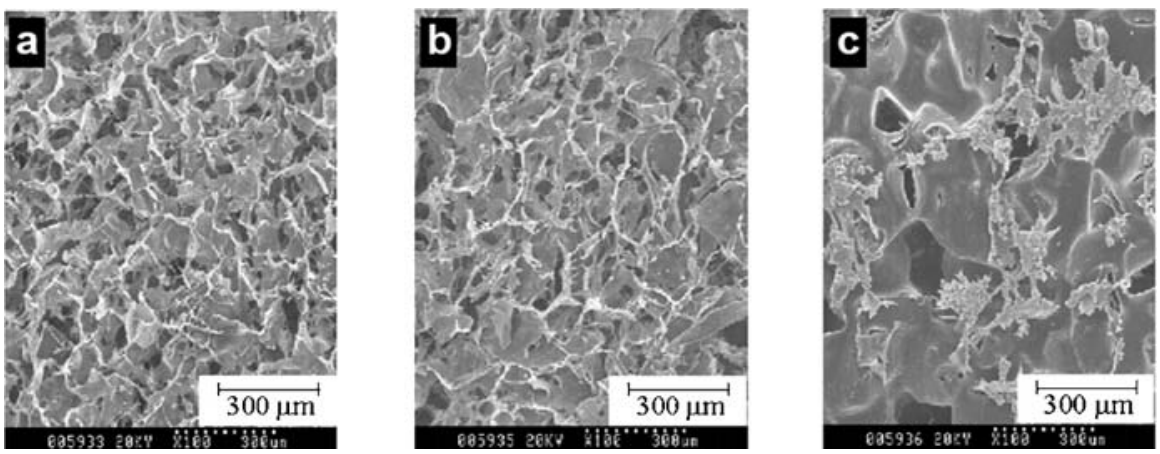

Fig. 8.11 Scanning electron micrographs of cells attached on a collagen matrix (a), a collagen matrix containing $9.6 \% \mathrm{HA}(\mathbf{b})$ and a PU matrix $(\mathbf{c})$. (magnification $\times 100)$ 
containing epithelial growth factor. Nonetheless, this method still required at least a week for the complete fabrication, and employment of growth factors holds a risk of oncogenesis induction.

To produce an artificial skin, autologous dermal fibroblasts of rat were seeded into the EDC crosslinked porous collagen-laminin membrane and cultured in minimum essential medium (MEM) for 3 days to provide the cell-niche adaptation period. 3-day culture is not enough for complete proliferation of cells into pores, but cells were firmly attached and anchored onto the superficial layer of the porous membrane due to specific cell adhesive characteristics of -RGD-sequences in col-

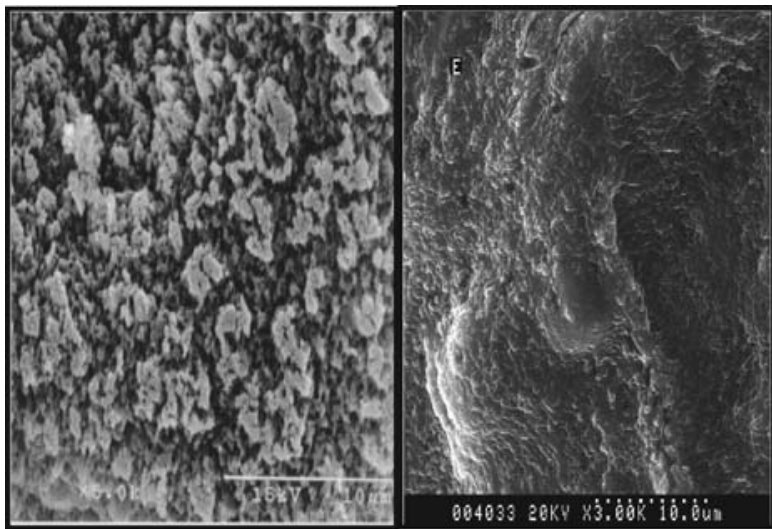

a

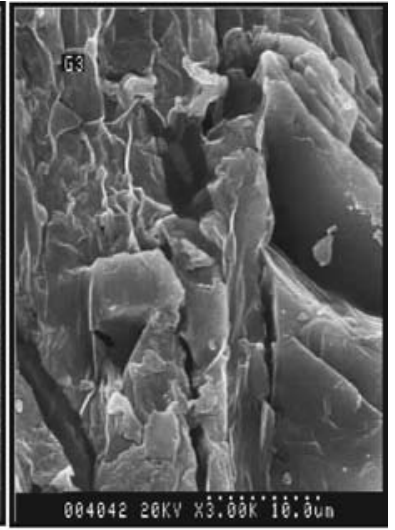

C

Fig. 8.12 Surface characteristics of HA microparticles obtained by encapsulation method (a: with only HA, X5K, b: with addition of collagen and antibiotics, X3K) and granulated method (c, with addition of collagen and antibiotics, $\mathrm{X} 3 \mathrm{~K}$ )

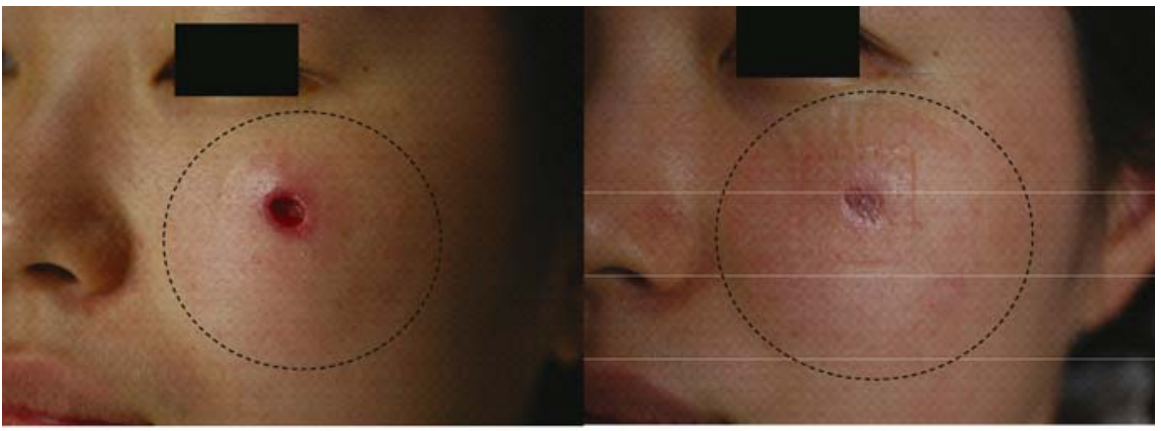

a

b

Fig. 8.13 a A facial subcutaneous lesion (dot circle) was augmented by a porous antibiotics encapsulated hyaluronic acid hybridized type I atelocollagen implant and dense-porous double layered collagen membrane was applied as a wound dressing. b After 3 weeks, subcutaneous dermal wound was completely recovered, and epithelial regeneration was conducted 


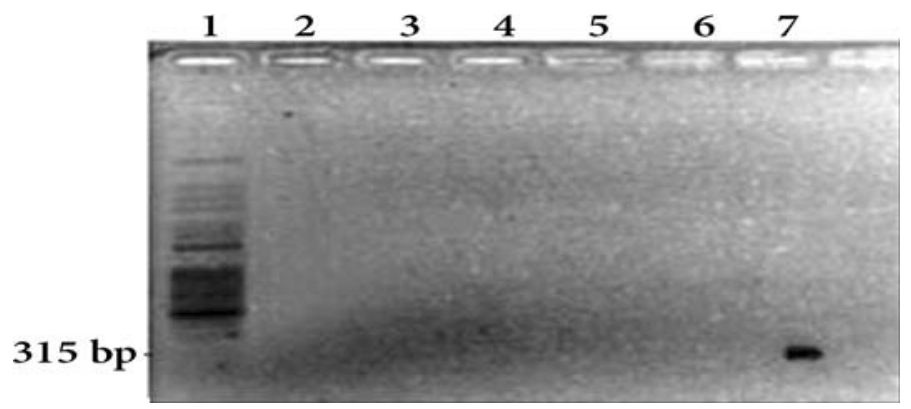

Fig. 8.14 Electrophoretic analysis of mycoplasma polymerase chain reaction (PCR). Supernatants from cell cultures on PLGA or collagen nanofibrous membrane were subjected to the sample preparation. Lane 1: size marker (100 bp DNA ladder), lane 2: collagen nanofiber with cells, lane 3: PLGA nanofiber with cells, lane 4: medium with cells, lane 5: medium without cells, lane 6: negative control (water) and lane 7: positive control

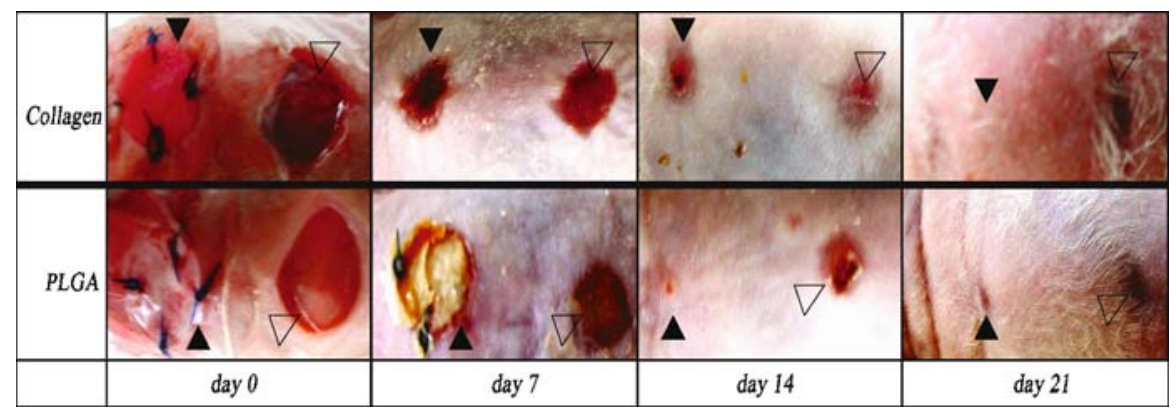

Fig. 8.15 Macroscopic observation of wounds treated with fibroblast seeded collagen nanofibrous or PLGA nanofibrous membrane at day 0, day 7, day 14 and day 21 after implantation. (Black arrow head: membrane placed area. Blank arrow head: non-treated control area)

lagen and laminin. After 4 weeks of coverage onto a grade 3 skin wound, dermis was completely replaced, and basement membrane lined beneath the dense layer as the seeded dermal fibroblasts were cultured in situ. Epithelial regeneration upon the dense layer surface was poor and partially occupied by the keratinocytes, but full coverage by epithelium was observed after 6 weeks. This phenomenon can be understood as the porous collagen based membrane can play as a vehicle for dermal autologous cell delivery, and the reconstructed basement membrane, which is a keratinocyte supplying bed in nature, has driven epithelial conduction. Later, a collagen-elastin nanofiber was fabricated as previously described, and the extruded fibers were brought onto collagen gel and crosslinked by EDC. Using nanofiber made it possible to produce a lattice controlled matrix, and uniformly aligned lattices conducted cells to proliferate into the designed lattice pattern [11-17] (Figs. 8.9-8.16). 


\section{Control}
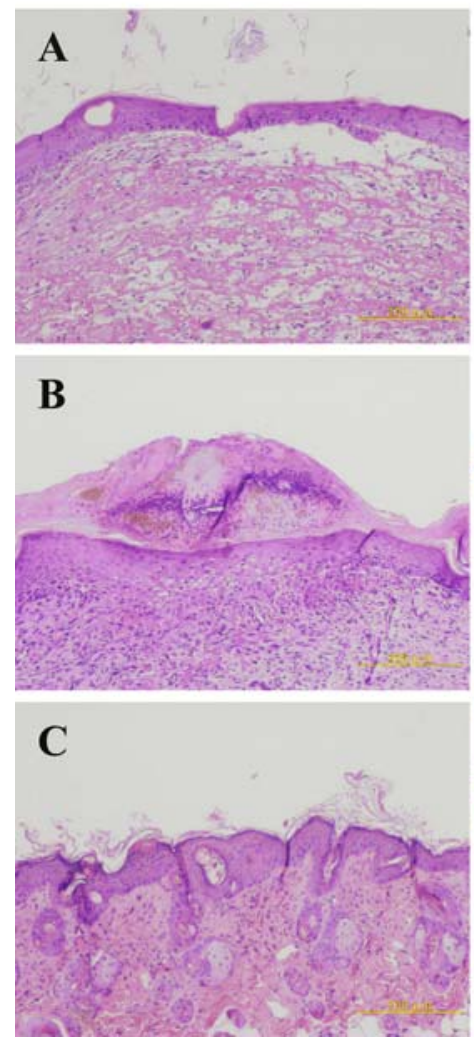

Colgn Nano

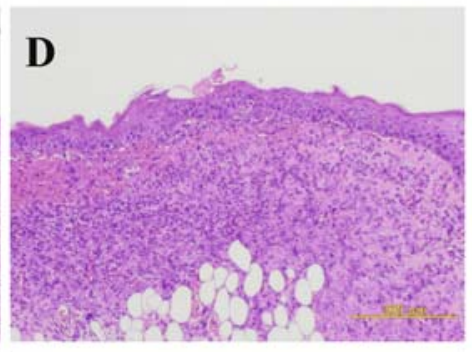

7 days

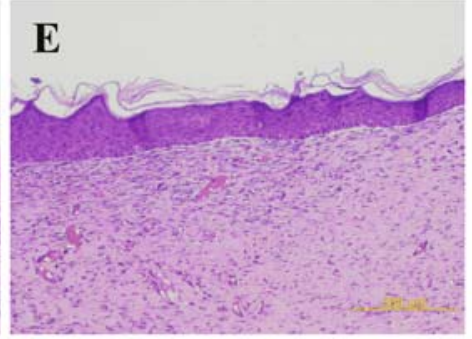

14 days

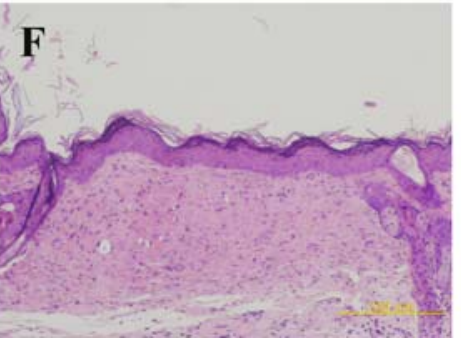

\section{1 days}

Fig. 8.16 Photomicrographs of biopsy specimens from a wound treated with fibroblast seeded collagen nanofibrous membrane on the postoperative 7th day $(\mathbf{A}, \mathbf{D}), 14$ th day $(\mathbf{B}, \mathbf{E})$, and 21th day $(\mathbf{C}, \mathbf{F})$. Nanofibrous membrane implantion $(\mathbf{D}, \mathbf{E}, \mathbf{F})$ and sham-operation controls $(\mathbf{A}, \mathbf{B}, \mathbf{C})$ were compared (Magnification 40X)

\subsubsection{Bone Reconstruction}

Collagen gel hybridized with calcium phosphate is applicable as a bone conductive substitute. Apatite $\left(\mathrm{Ca}_{10}\left(\mathrm{PO}_{4}\right)_{6}^{++}\right)$, a typical inorganic component of skeleton, was synthesized and heated at $980^{\circ} \mathrm{C}$ after which apatite crystals were not sintered but degradable by hydrolysis. $1 \%$ collagen gel was mixed with the apatite in 12:88 $\mathrm{w} / \mathrm{v}$, and the mixture was crosslinked. Then the produced apatite-collagen pellet was implanted into rabbit's resected tibiae. 4 weeks after implantation, the resected defect was completely regenerated by host bone with cortical bone continuity and cancellous bone stroma, and after that, typical bone remodeling process followed to produce natural bone. However, mechanical strength of the regenerated area was less than general bone. 
Although collagen based gel is favorable to fabricate cell conductive substitute, weak mechanical property is a barrier for application in the physiological stress bearing tissues, and, to resolve this problem, hybridization of collagen with polymeric biomaterials has been suggested. Introducing functional groups on esters, such as polyurethane (PU) and poly lactic-glycolic acid (PL-GA), through treatment with ozone induces surface oxidization that produces carboxyl groups on the surface which react with amines in collagen.

As the apatite-collagen provided insufficient strength despite promotion of a favorable osteogenesis, collagen was grafted onto the biodegradable PLA membrane to reinforce the strength. PLA of M.W. 50,000 was resolved by $99 \%$ chloroform solution to produce $9 \%$ (W/V) PLA solution, and $\mathrm{NaCl}$ crystals $(425-500 \mu \mathrm{m})$ were mixed to the PLA solution with adjusting $\mathrm{NaCl}$ :PLA ratio to 9:1 (w/w). The prepared solution was cast into an appropriate shape, and the solvent was allowed to evaporate over $24 \mathrm{hrs}$ to produce a porous membrane after leaching out the $\mathrm{NaCl}$ particles with distilled water. To induce molecular bindings between the collagen within apatite-collagen composite and the PLA membrane surface, PLA membrane was oxidized by ozone to produce reactive carboxyl and hydroperoxide groups on the PLA surface. After the ozone treatment at $60 \mathrm{~V}$ for $60 \mathrm{~min}$, apatite-collagen was delivered onto the ozone treated PLA membrane to produce an apatite-collagen grafted PLA membrane. The grafted membrane was pressed $\left(1\right.$ bar at $\left.37^{\circ} \mathrm{C}\right)$ from vertical direction, and then EDC collagen cross-linking was performed to integrate the mixed atelocollagen fibers in the grafted material. The final product was im-

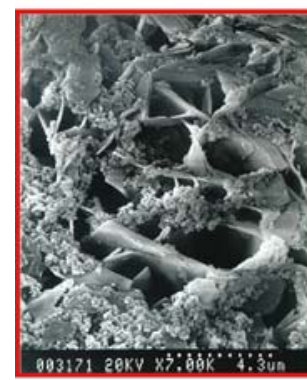

Carbonate Apatite synthesized at $58^{\circ} \mathrm{C}$

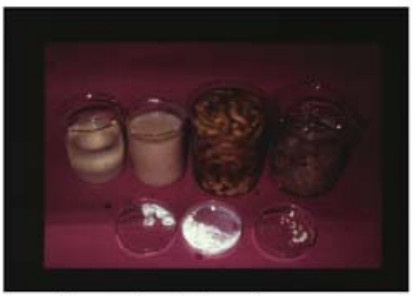

Type I atelocollagen from umbilical cord

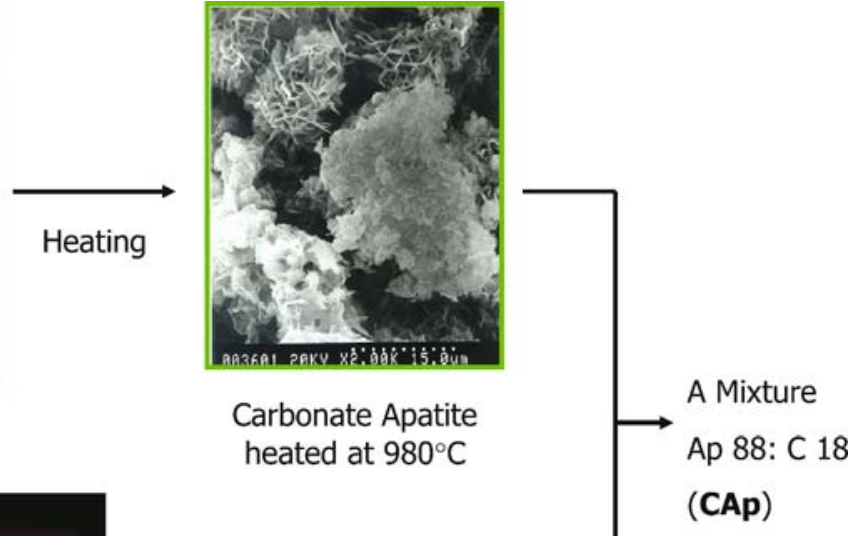

(CAp)

Fig. 8.17 Scheme of producing carbonate apatite-collagen substitute mimicking bone 


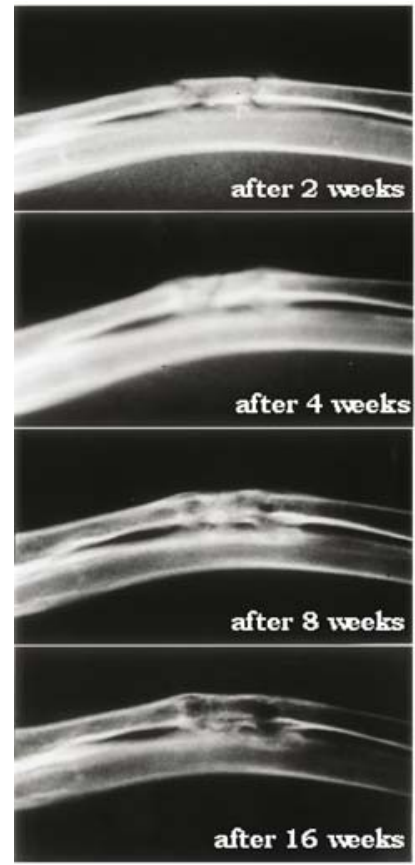

a

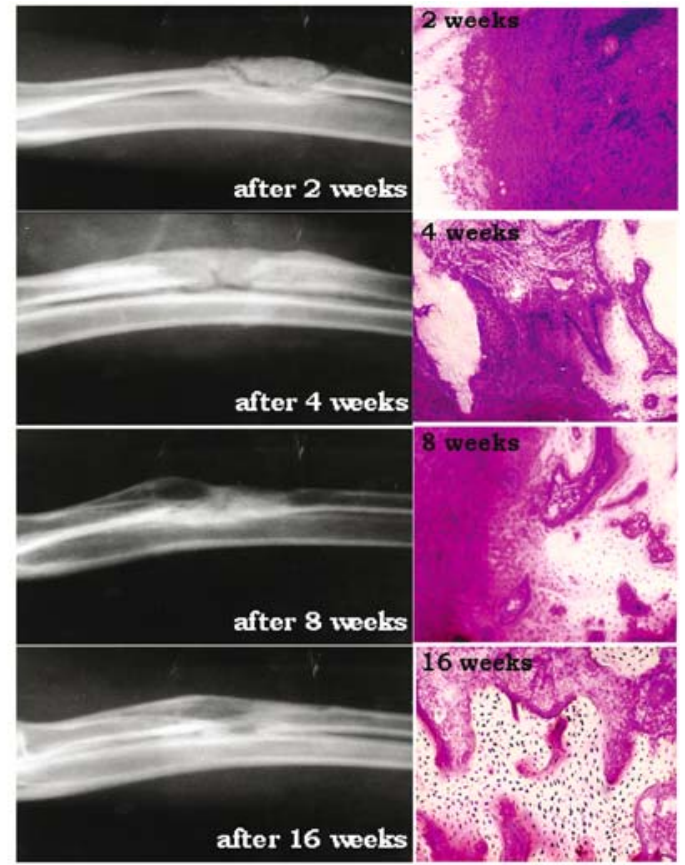

b

Fig. 8.18 Radiological view of the carbonate apatite-collagen implanted in the resected tibiae of rabbits for $16 w k s$. a autograft, $\mathbf{b}$ apatite-collagen implant and histological view

planted into oval defects induced on rabbit's calvarial bone. The bone was regenerated in a similar manner to that of apatite-collagen implanted model, and the supportive PLA membrane was gradually degraded as the bone was replaced [18-25] (Figs. 8.17-8.23).

\subsubsection{Esophagus Replacement}

Collagen grafted synthetic polymer is applicable to soft tissue replacement as well. Except the air passages such as trachea and bronchus which require almost no repeating dilatation-shrinkage action of compliance, most of the tubular-shaped tissue requires various level of compliance against the mass passing through lumen, as arteries to pulsating blood flow and esophagus to swallowing dietary mass. In general, tubular walls of those tissues consist of multiple-layered smooth muscle cells to resist against pressure at luminal wall exerted by transporting mass, and appropriate flexibility is required.

To replace esophagus, polyurethane, a bioinert biomaterial with mechanical advantage of high durability against continuous bending stresses, was employed. 
An approach is presented for graft copolymerization of type I atelocollagen onto surface of polyurethane (PU) treated with ozone. Through surface oxidization by ozone to modify the PU surface, peroxide groups are easily generated. Those peroxides are broken down by redox-polymerization and provide active species which initiate graft polymerization by reacting with amines in the collagen molecules. Ozone oxidation time and voltage could readily control the amount of peroxide production. Maximum concentration of peroxide was about $10.20 \times 10^{-8} \mathrm{~mol} / \mathrm{cm}^{2}$ when ozone oxidation was performed at $60 \mathrm{~V}$ for $30 \mathrm{~min}$. After the reaction of PU by ozone oxidation, type I atelocollagen gel was graft copolymerized onto the PU. All the physical measurements on the collagen grafted surface indicated that the PU surface was effectively covered with type I atelocollagen. Interaction of the collagen grafted PU surface with fibroblasts could be greatly enhanced by the surface graft polymerization with type I atelocollagen. Attachment and proliferation of fibroblasts on the grafted type I atelocollagen were significantly enhanced, and it is assumed that the atelocollagen matrix supported the initial attachment and growth of cells. In the early stage of proliferation, collagen synthesis in fibroblasts was not activated and remained at a relatively low level due to the grafted type I atelocollagen, increasing only fibroblast differentiation. The mechanical property of tubular tissue was oriented from the alignment of cells that consists of repeated overlayers of longitudinal and circumferential layers and forms wall thickness.
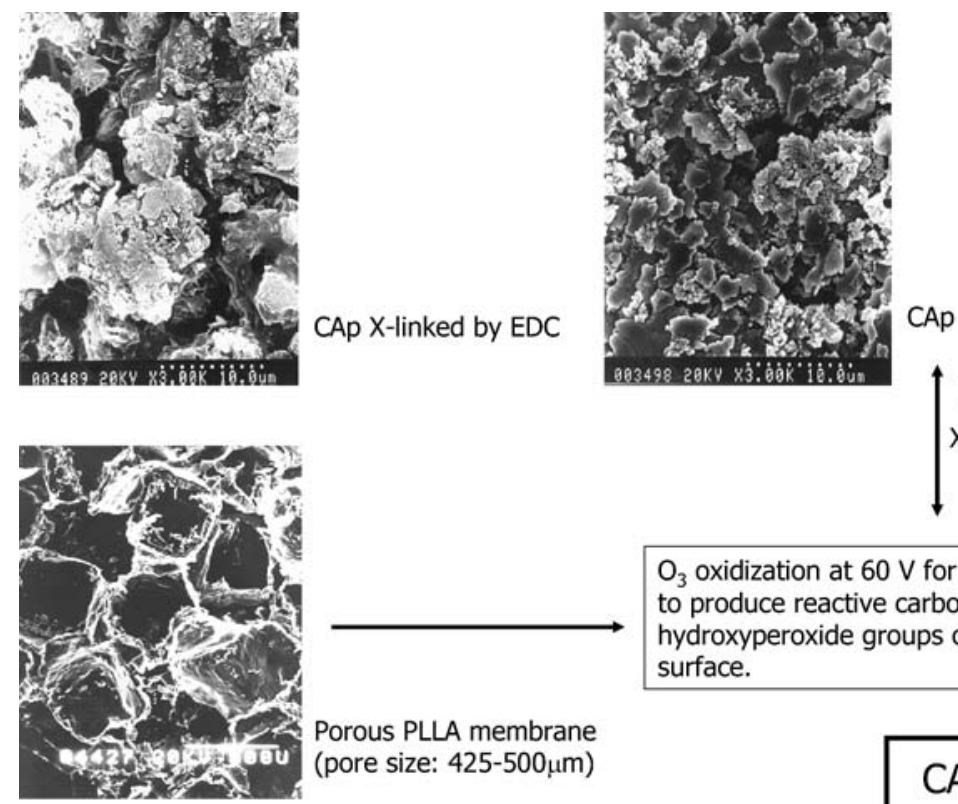

Hybridization

X-linked by EDC

$\mathrm{O}_{3}$ oxidization at $60 \mathrm{~V}$ for $60 \mathrm{~min}$ to produce reactive carboxyl and hydroxyperoxide groups on PLLA surface.

(pore size: $425-500 \mu \mathrm{m}$ )

CAp + PLLA

Fig. 8.19 Production of a carbonate apatite-collagen composite hybridized with a porous poly(L-lactic acid) membrane as a membranous bone implant 


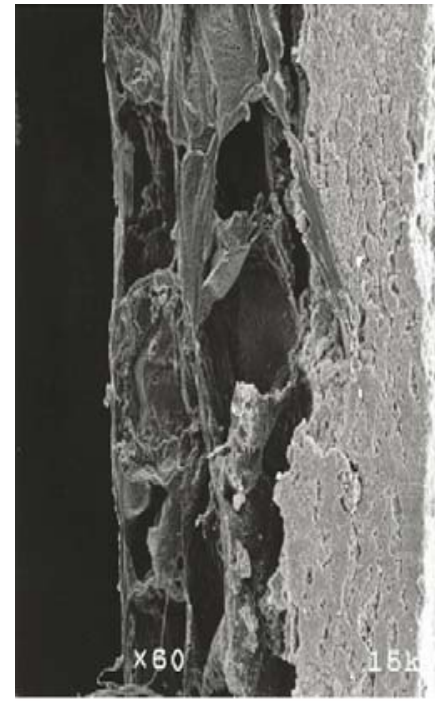

a
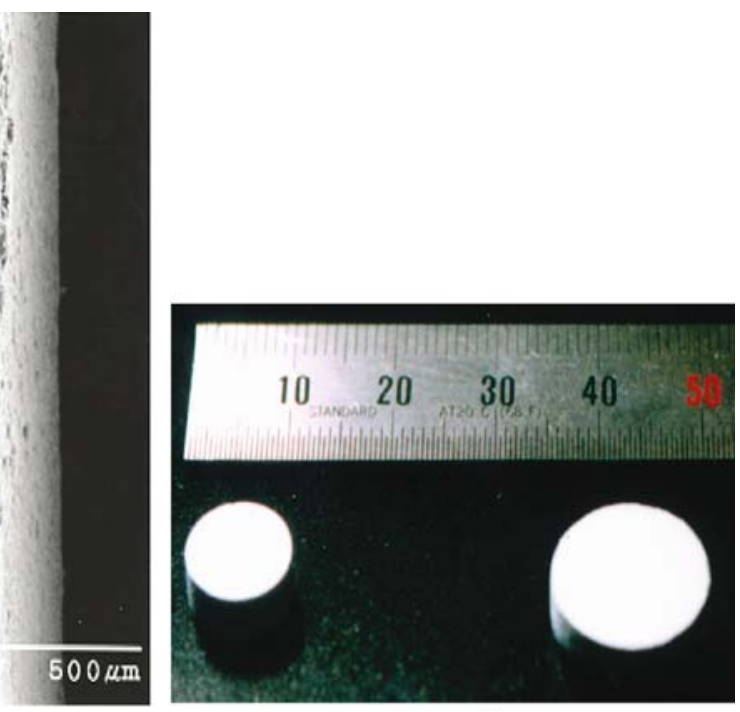

b

Fig. 8.20 A collagen-apatite-PLLA substitute (SEM) (a), and produced pellet (b)
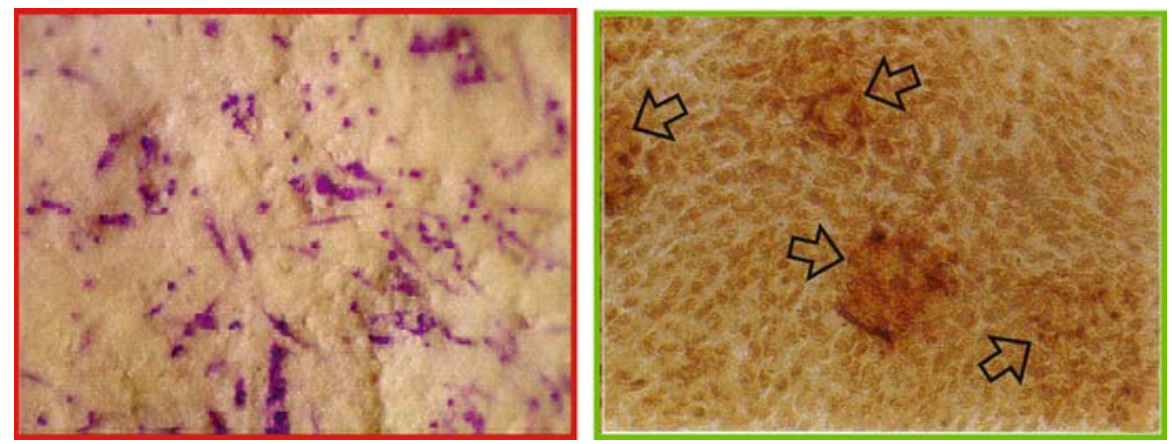

Fig. 8.21 Osteoblasts attached onto CAp + PLLA membrane. Arrows indicate calcium deposit after 3 days of culture

Regarding this result, a double layered PU tubular scaffold grafted with collagen was fabricated to produce an artificial esophagus. PU purification was performed by diluting PU particles in DMAC(dimethyl-acrylamide) solution then precipitating in non-solvent methanol, and drying the precipitate under vacuum for 2 days to remove residual methanol. After purification, PU was dissolved in DMAC solution at the final concentration of $13 \% \mathrm{w} / \mathrm{w}$. Glass rod, with diameter of $3 \mathrm{~mm}$ and length of $15 \mathrm{~cm}$, was worn with $13 \%$ PU solution and then air-dried for 6 hours. This process was repeated twice. After wearing, an end part of the glass rod was cut, and then the rod was worn again in reverse direction by the same process to be uniformly worn. It was dried under vacuum for 12 hours afterward. Completely dried sam- 

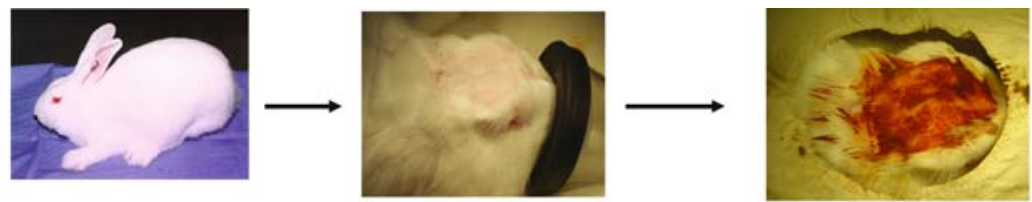

New Zealand white rabbit Anesthetized with Aseptic preparation of surgical ketamin and xylazine field with betadin solution

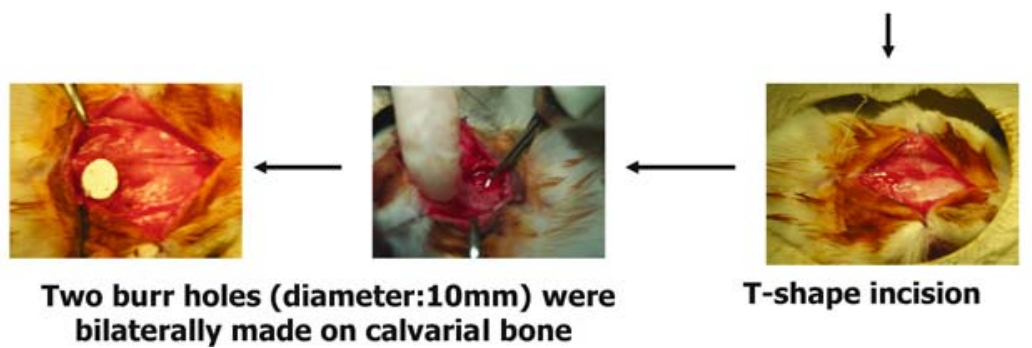

Fig. 8.22 In vivo experiment of the CAp - PLLA on to the rabbit calvarial bone defect bone model

CAp + PLLA

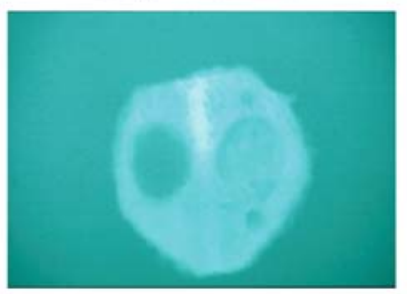

- MRI

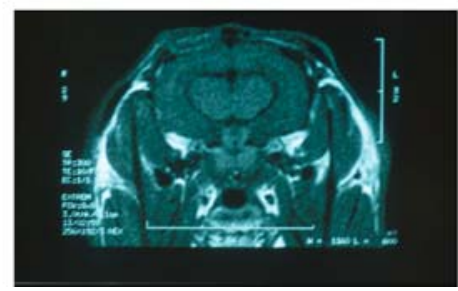

CAp
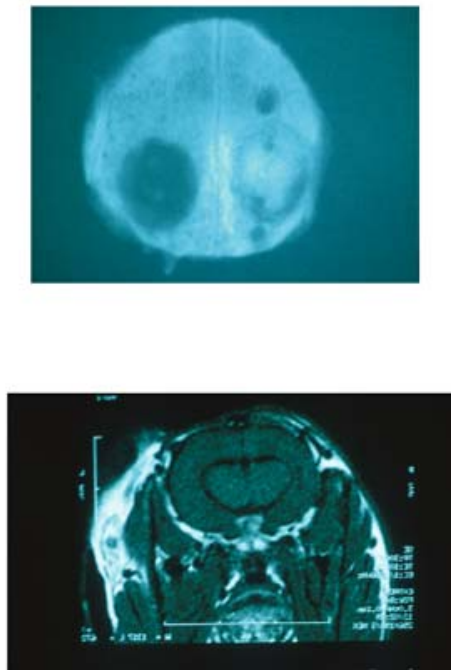

Fig. 8.23 Both implanted lesion were completely replaced by the host bone, and on the boneremodeling process. CAp + PLLA membrane implant demonstrated a higher structural integration than CAp

ple was swelled in benzene solution for 1 hour and washed with distilled water for 2 hours and ethyl alcohol for 1 hour. After swelling and wearing process, a porous PU tube was separated from glass rod and dried under vacuum. To graft collagen, ozone treatment was performed as described above. The tube was immediately immersed in $1 \%$ type I atelocollagen gel, and Mohr's salt $\left[\mathrm{FeSO}_{4}\left(\mathrm{NH}_{4}\right) 2 \mathrm{SO}_{4} 6 \mathrm{H}_{2} \mathrm{O}\right]$ 
was added to the gel to decompose peroxides. Then polymerization was allowed to proceed at $35^{\circ} \mathrm{C}$ and $\mathrm{pH}$ 8.0. Type I atelocollagen grafted porous PU tube was dried in vacuum at $25^{\circ} \mathrm{C}$. The tube was dipped in a $2 \%$ collagen gel and crosslinked by EDC later. By this procedure, a porous collagen-grafted tube with inner diameter of $3 \mathrm{~mm}$, thickness of $0.7 \mathrm{~mm}$ covered by dense collagen layer was produced. Rabbit's esophageal smooth muscle cells were seeded and cultured in a mechanically stressful environment of $10 \%$ strain magnitude and $1 \mathrm{~Hz}$ frequency. Culturing for 18 hours of mechanically stretching condition and 6 hours of stationary condition on every 24-hour period, the cultured cells aligned in the perpendicular direction to the strain direction after 2 days. The collagen grafted PU tube with cell alignment control was subcutaneously implanted in nude mice for 4 weeks, and a histological finding demonstrated that a well-aligned smooth muscle cells reconstructed the tube which is applicable for replacement of esophagus [26-30] (Figs. 8.248.26).

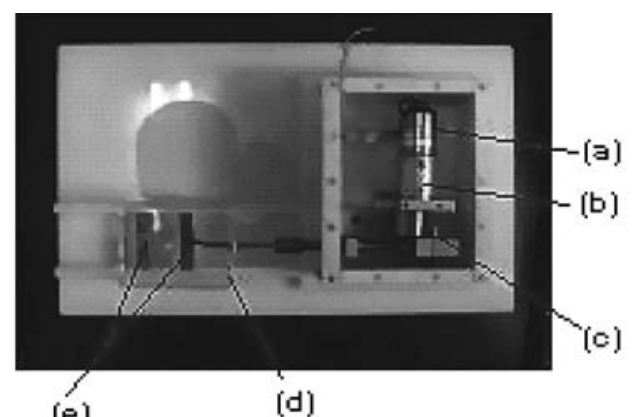

(e)

(d)

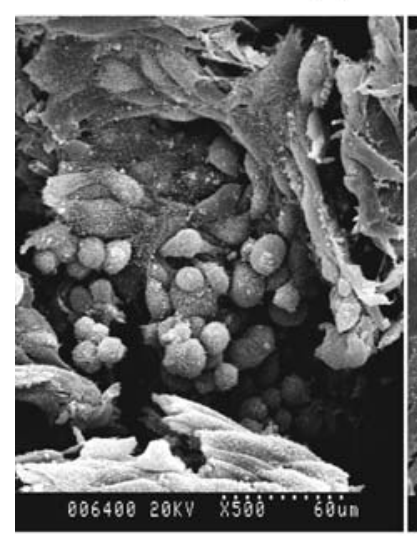

a

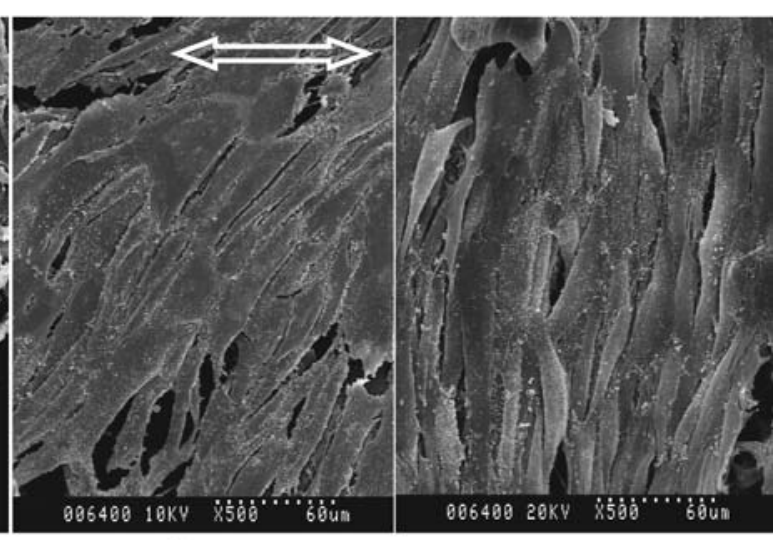

b

C

Fig. 8.24 Cyclic $10 \%$ strain magnitude and $1 \mathrm{~Hz}$ frequency was applied by a self-designed stretching chamber. $a$ DC motor, $b$ Gear box, $c$ Cam system, $d$ Quartz chamber, $e$ Forcepses. Cell cultured under white arrow on $\mathbf{b}$ indicates the strain direction. a rabbit esophageal smooth muscle cell seeded into a collagen grafted porous polyurethane tube, $\mathbf{b}$ cultured for $12 \mathrm{hrs,} \mathbf{c}$ cells aligned in perpendicular to the strain axis after 24 hours of culture 

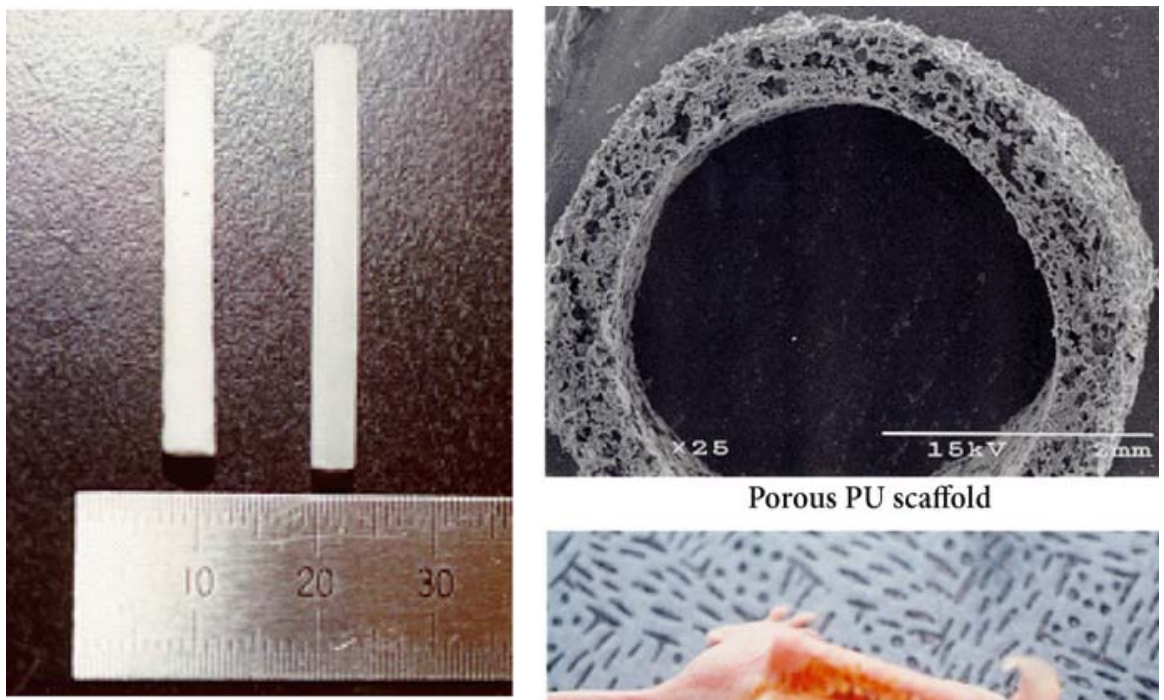

Porous PU scaffold

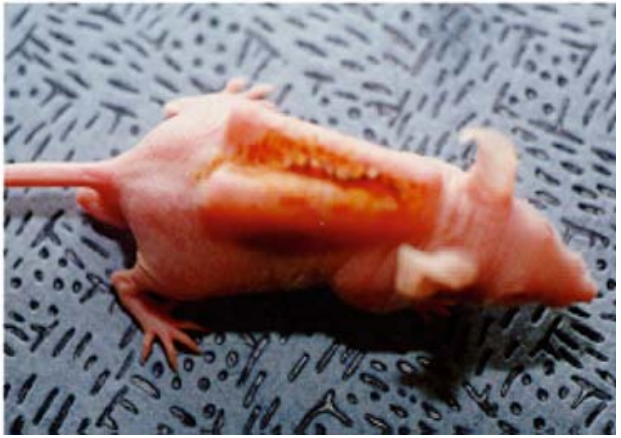

Fig. 8.25 An artificial esophagus consists of rabbit smooth muscle cells dynamically cultured in a type I atelocollagen grafted porous polyurethane tube was subcutaneously implanted in a nude mouse

\subsubsection{Wound Healing promoting Anti-Adhesive Matrix}

The idea of collagen grafting was also applied to produce a healing-promoting antiadhesive membrane that is particularly necessary in peritoneal surgery to prevent postoperative adhesion. At first, glycolide and D,L-lactide were recrystallized from ethyl acetate and dried under vacuum before use. Lactide and glycolide, at a molar ratio of 75:25, were put into a glass ampoule, and $\mathrm{mPEG}$ was added for preparing the mPEG-PLGA block copolymer through ring-opening polymerization. $0.05 \%(\mathrm{w} / \mathrm{w})$ of stannous octoate added to the solution as a catalyst. The ampoule was evacuated by a vacuum pump, sealed with a torch, and was heated in an oil bath at $130^{\circ} \mathrm{C}$ for $12 \mathrm{hrs}$. After the reaction was complete, resulting polymers were purified by dissolving in methylene chloride and then precipitated in excess methanol.

Obtained polymers were dried in vacuum. For the preparation of polymer film, $8 \%$ solution of mPEG-PLGA in chloroform was cast on a glass plate, and the solvent was evaporated in a vacuum oven for 2 days. On the other side, a porous collagen-hyaluronic acid (HA-Col) membrane was fabricated and crosslinked. 1\% of hyaluronic acid (HA) (sodium salt, $\mathrm{Mw}=120,000-150,000$ ) as an aqueous so- 


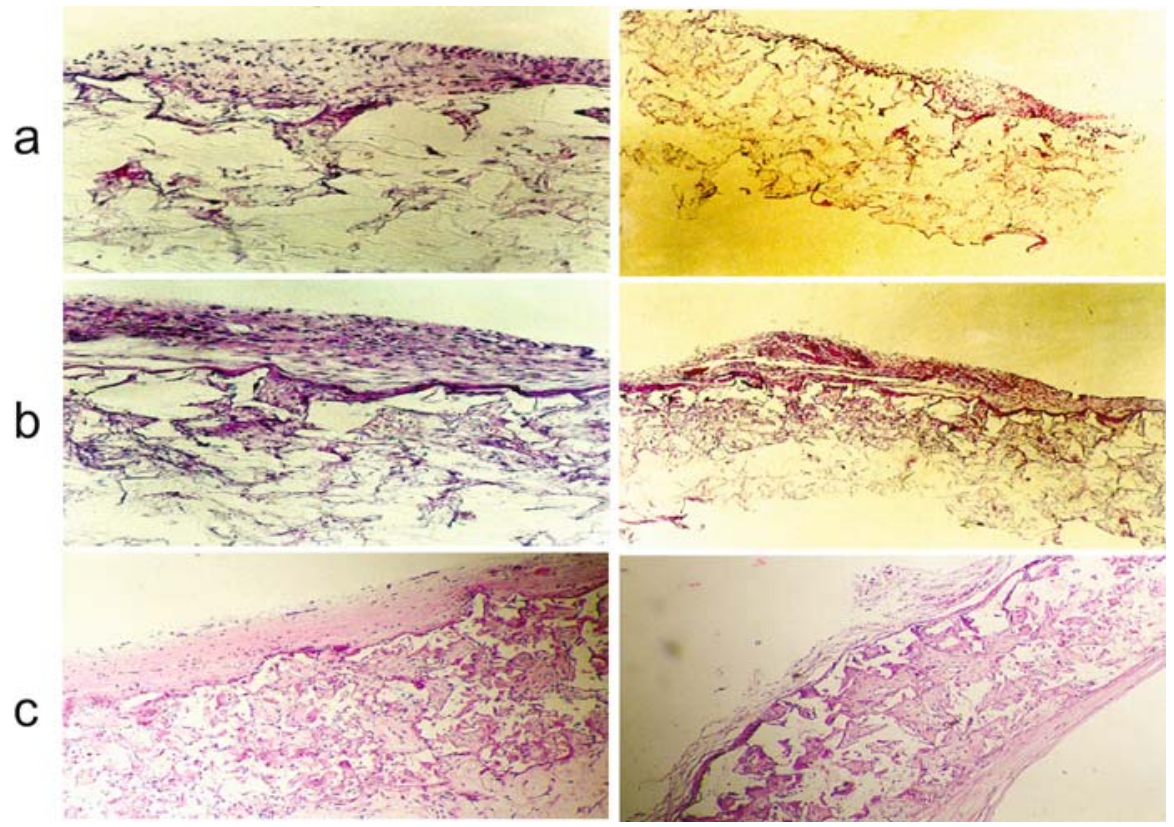

Fig. 8.26 Histological observation of the implanted artificial esophagus demonstrated a well aligned smooth muscle cells reconstructing the tube

lution was added to $1 \%$ Type I atelocollagen gel, forming $20 \%(\mathrm{w} / \mathrm{w}) \mathrm{HA} / \mathrm{collagen}$ solution and homogenized at $8000 \mathrm{rpm}$ for 3 minutes at $4{ }^{\circ} \mathrm{C}$. The resulting slurry was poured into a well plate, frozen at $-70^{\circ} \mathrm{C}$, and then lyophilized at $-50^{\circ} \mathrm{C}$. The fabricated porous HA-Col membranes obtained were immersed in $50 \mathrm{mM}$ of EDC solution $\left(\mathrm{H}_{2} \mathrm{O}\right.$-ethanol $\left.=5: 95\right)$ for $24 \mathrm{hrs}$. Obtained membranes were washed in distilled water by a sonicator, and then re-lyophilized at $-50^{\circ} \mathrm{C}$. To promote cell adhesion, the HA-Col membranes coated with various concentrations of fibronectin(FN) were prepared by applying $1 \% \mathrm{FN}$ solution over the HA-Col membranes at doses of $50 \mu \mathrm{g} / \mathrm{cm}^{3}$ and incubation at $37^{\circ} \mathrm{C}$ under humid condition for 5 hours.

To prepare HA-Col and mPEG-PLGA bi-layered composite membrane, chloroform was sprayed on the surface of mPEG-PLGA film, and then cross-linked HAFN-Col membrane was loaded on the slightly dissolved surface of mPEG-PLGA film. In vitro adhesion test revealed that fibroblasts attached better on HA-Col membrane compared to those on mPEG-PLGA film, PLGA film or oxidized cellulose film. mPEG-PLGA film had the lowest cell adhesive property. In confocal microscopic observation, the actin filaments were significantly more polymerized when 50 or $100 \mu \mathrm{g} / \mathrm{cm}^{3}$ fibronectin was incorporated on the HA-Col membranes. After 7-day culture, fibroblasts penetrated throughout the HAFN-Col network and the cell density increased whereas very few cells were found attached on surface of the mPEG-PLGA film. In vivo evaluation by implantation test for 7 days in rabbit's peritoneal wound showed that the composite membrane could protect tissue 

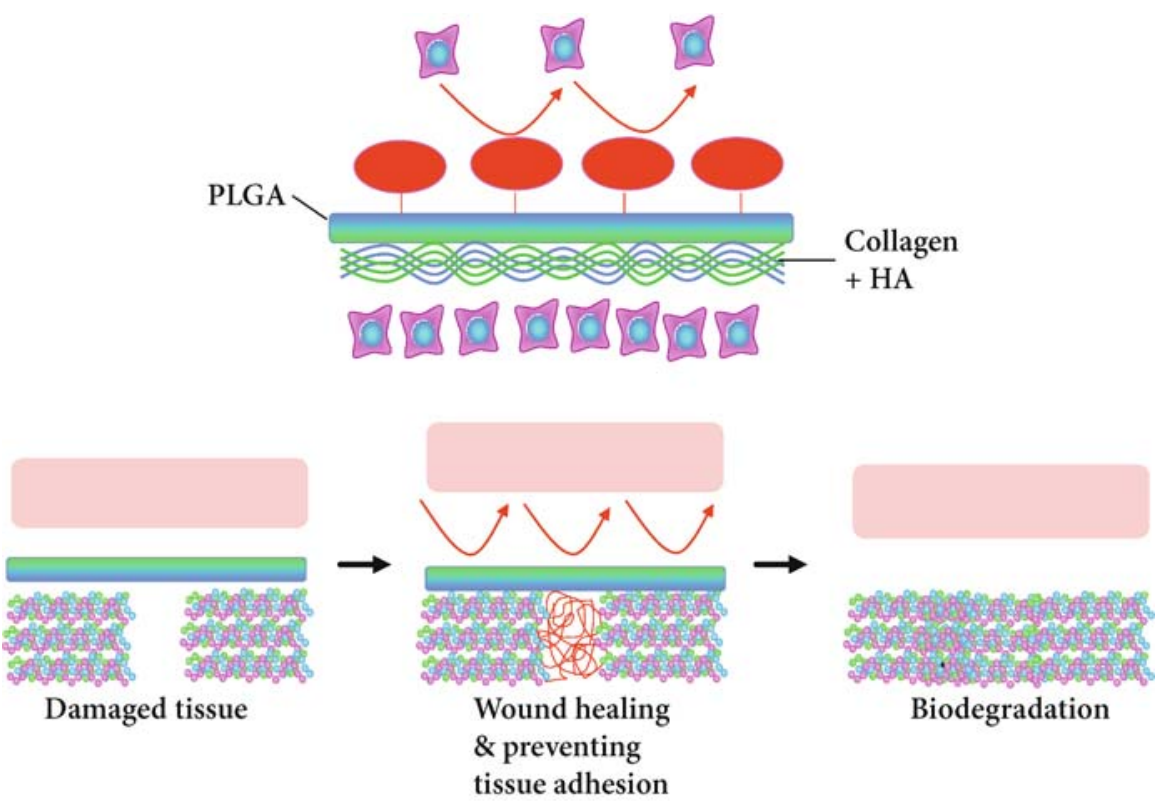

Fig. 8.27 While the hydrophilic polyethylene glycol molecules on the biodegradable polylacticglycolic acid (PLGA) membrane inhibit the adhesion of neighboring cells, the collagen and hyaluronic acid containing fibronectin porous layer grafted on the other side of PLGA membrane promotes wound healing. The PLGA membrane may gradually be degraded

adhesion during the critical period of peritoneal healing and did not provoke any inflammation or adverse tissue reaction [31,32] (Figs. 8.27-8.32)

\subsubsection{Liver Regeneration}

Collagen based biomaterial was also applied as a mesenchymal stem cell (MSC) delivery vehicle. Liver hepatocyte is a representative stable cell that has tremendous proliferative capacity and ability to differentiate and proliferate when injury or damage occurs in liver. In case of no-proliferation of hepatocytes, oval cells are stimulated to divide and eventually differentiate into mature hepatocytes; therefore, an oval cell is regarded as a compensatory cell in liver injury, and has been concerned to be equivalent to liver stem/progenitor cells. Oval cell is oriented from bone marrow mesenchymal cell, and is a facultative bipotential precursor cell that differentiates into hepatocytes or bile duct cells. Human MSCs harvested from tibial bone marrow and co-cultured with hepatocytes for 3 days in medium with additive hepatocyte growth factor (HGF) produced a confluent mixture of undifferentiated MSCs and oval cells. To purify the oval cells from nonparenchymal cells, cell cloning method was applied. Characterization of oval cells was performed by a double immuno- 


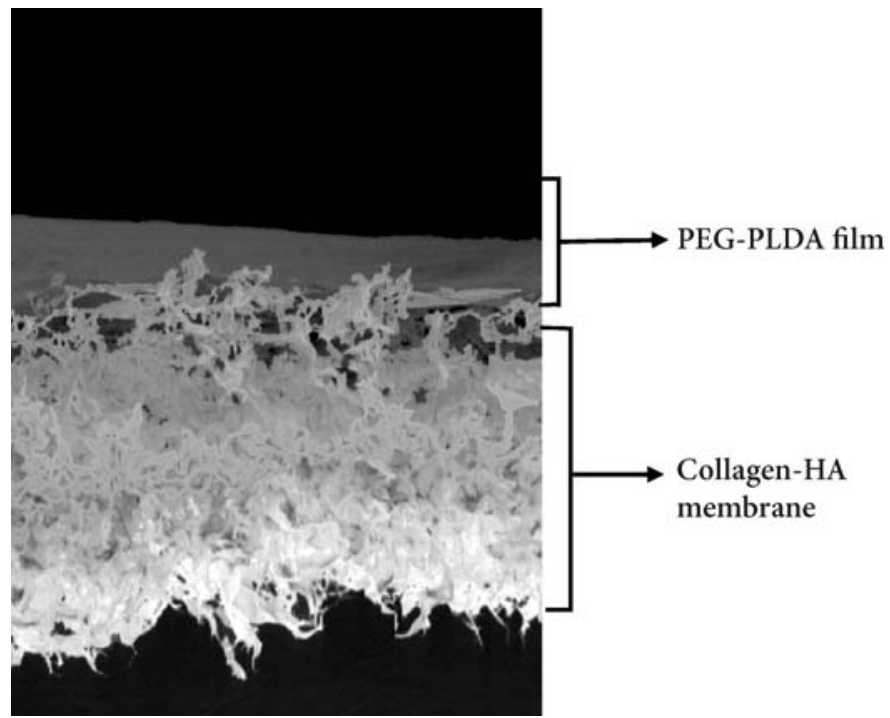

Fig. 8.28 The SEM observation of the composite matrix, which consists of a PEG-PLGA film and porous collagen-HA matrix containing fibronectin

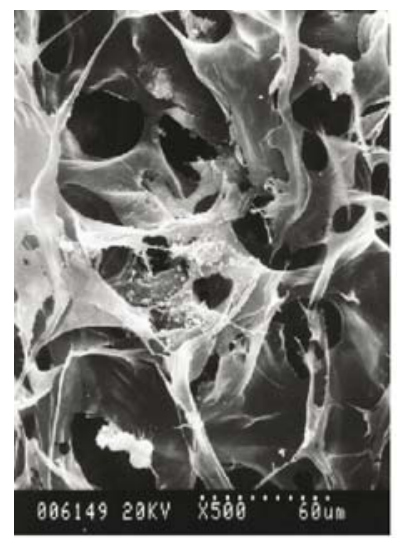

Collagen-HA membrane

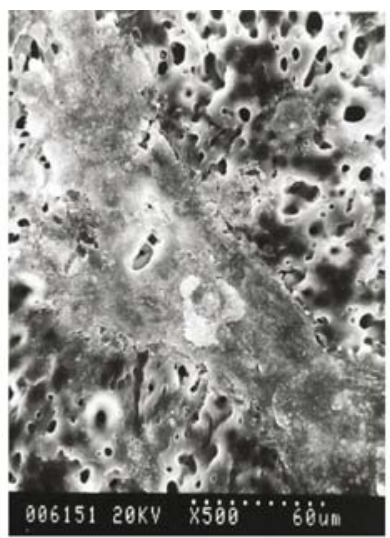

PLGA membrane

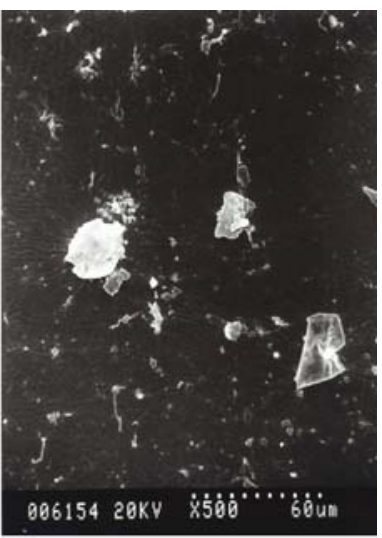

PEG-PLGA membrane

Fig. 8.29 Observed fiblasts on the PEG-PLGA surface were significantly fewer than on the PLGA membrane surface. Collagen-HA membrane demonstrated high affinity to cell attachment

fluorescence method using alpha-fetoprotein (AFP) and cytokeratin-19 monoclonal antibody expecting co-expression. Isolated human MSCs oriented oval cells were seeded on an EDC crosslinked porous type I atelocollagen matrix, and cultured in medium containing insulin, dexamethasone, and hydrocortisone as the hormone stimulators and additive cytokines of HGF and epidermal growth factor (EGF). For 


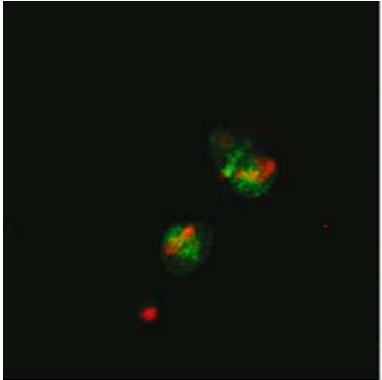

a

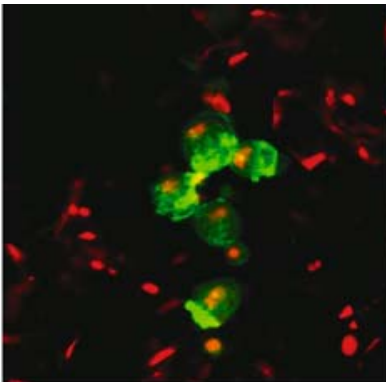

b

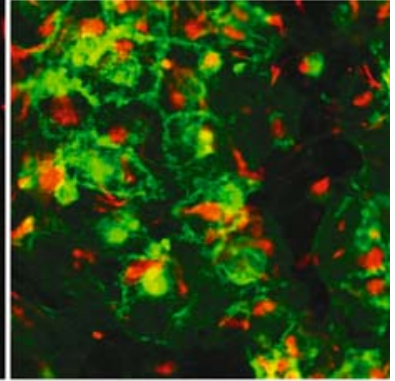

C

Fig. 8.30 Confocal microscopic images of FITC-phalloidin stained F-actin (green) and PI stained nucleus (red) in fibroblasts cultured on the PEG-PLGA film (a), collagen-hyaluronic acid membrane (b), $100 \mu \mathrm{g} / \mathrm{cm}^{3}$ fibronectin coated collagen-HA membranes (c)

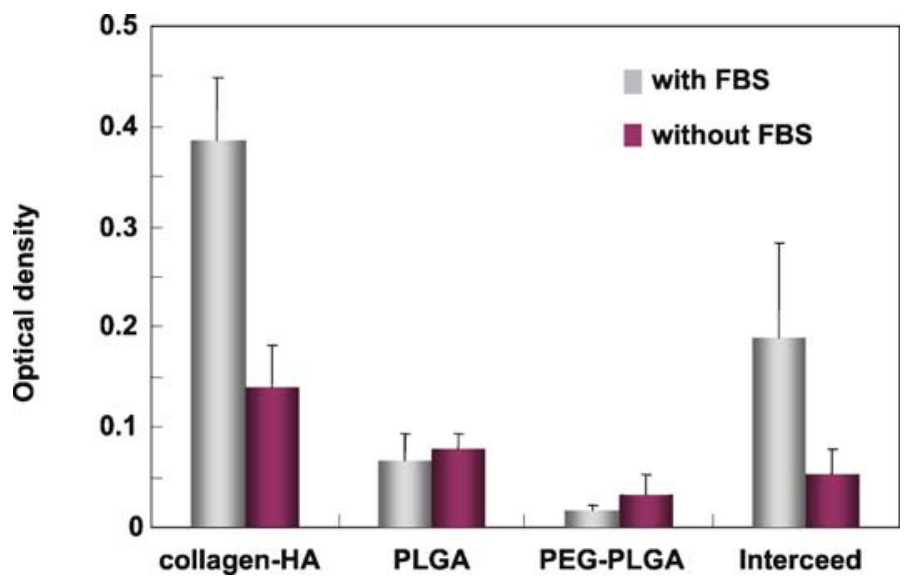

Fig. 8.31 Attachment of fetal human dermal fibroblasts on the various types of membranes 4 hours after seeding: Effect of fetal bovine serum in the culture medium. ${ }^{*}$ Interseed (Johnson \& Johnson Co.) is a commercially available anti-adhesive membrane made by oxidized cellulose

3 weeks, albumin secretion and urea detoxification rate continuously increased either in the hormone additive or the cytokine additive groups, and this was directive knowledge that avoidance of using growth factors in committing MSC-oriented oval cell toward hepatocyte can escape from risky induction to liver cancer. The collagen scaffold was able to foster long-term viability and protection of the cells, and this 3-dimensional culture of oval cells is considerable for designing a cell-delivering tool for hepatic disease [33] (Figs. 8.33-8.38). 


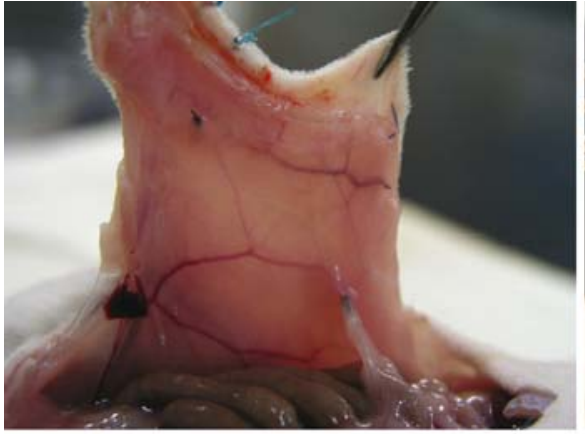

a

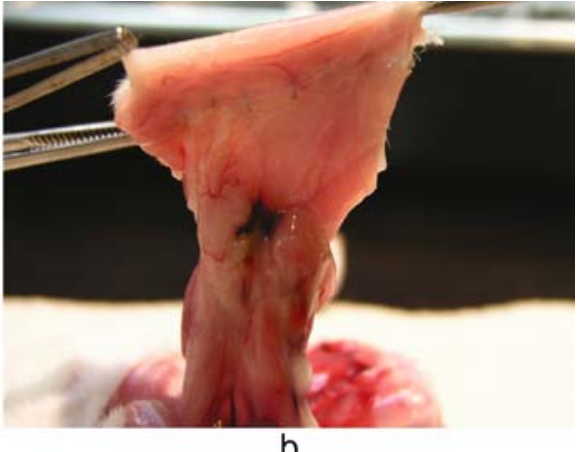

b

Fig. 8.32 In vivo Experiement: rat abdominal sidewall injury model Photographs of a Col-FN grafted PEG-PLGA membrane treated group and $\mathbf{b}$ control group (right) after 7 days. After an abdominal midline incision, a $2 \mathrm{~cm} \times 1 \mathrm{~cm}$ defect on the anterior abdominal wall of 30 female Sprague-Dawley rats was created by a template and scalpel. The Col-FN grafted PEG-PLGA membrane $(3 \mathrm{~cm} \times 2 \mathrm{~cm})$ was placed as the Col-FN grafted side could face the injured peritoneal wall. Asymmetric collagen-fibronectin grafted PEG-PLGA copolymer membrane was appeared to successfully reduce the incidence of postoperative adhesion formation

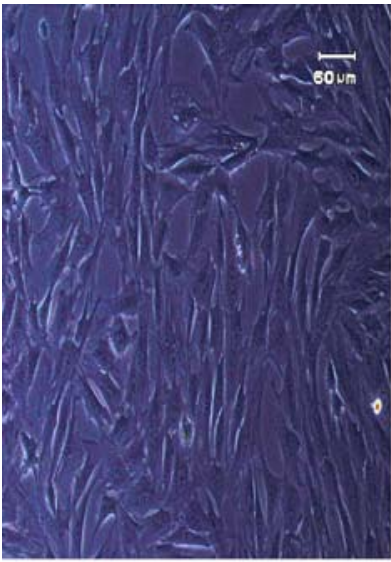

a

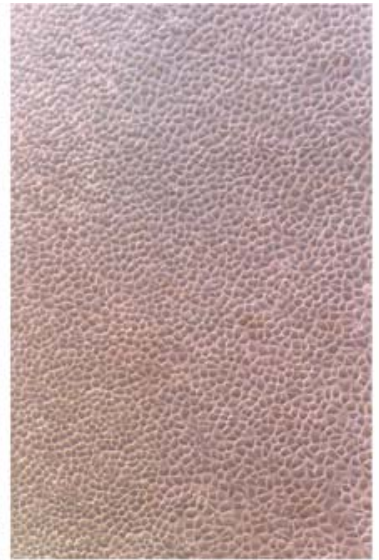

b

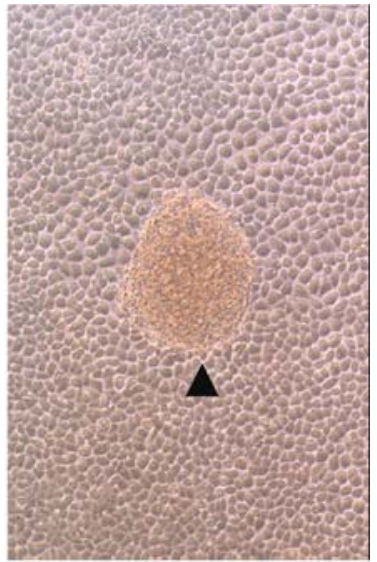

C

Fig. 8.33 Microscopically observed a mesenchymal stem cells co-cultured with hepatocytes on day $0, \mathbf{b}$ oval shaped cells on day 3 , c colony piled oval cells on day 24 in DMEM/F-10 culture media $(\times 100)$

\subsection{Discussion}

Although collagen is a favorable biomaterial to be employed in a wide range of fabrication procedures with cells, there is no established tool to isolate and produce absolute atelocollagen, the immune-free substitute, at present. Even a single remaining collagen dimer or trimer may cause immune reactions in future. The resource of collagen, especially for clinical applications is also important, because unknown 


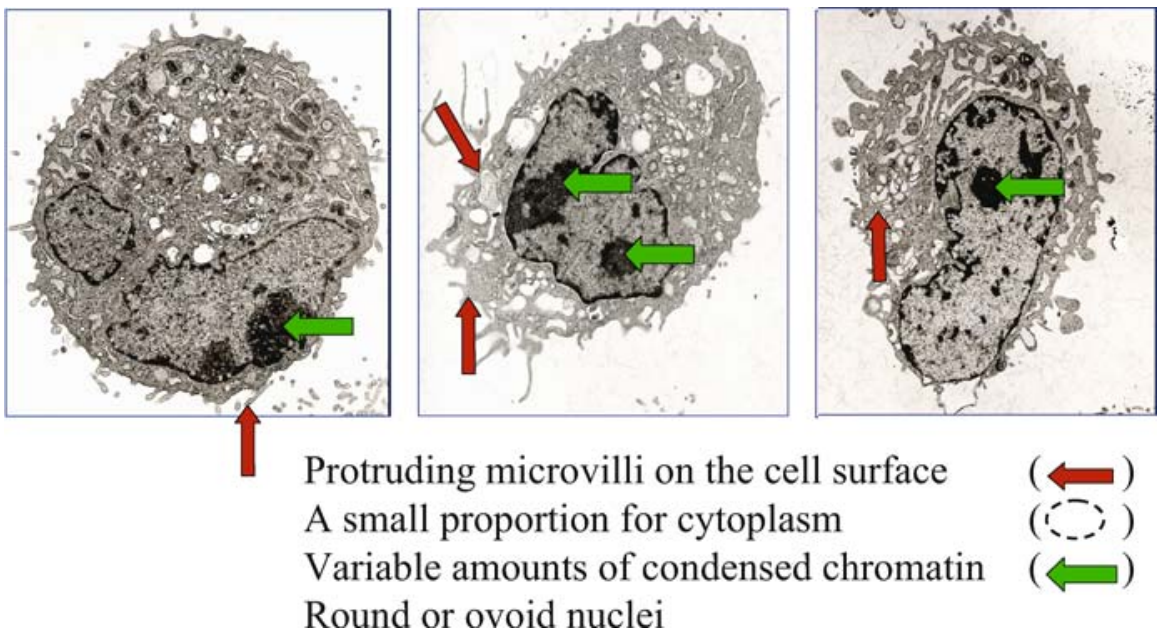

Fig. 8.34 The oval cells obtained from mesenchymal stem cells through co-culture with hepatocytes demonstrated typical cytomorphorlogcal characteristics

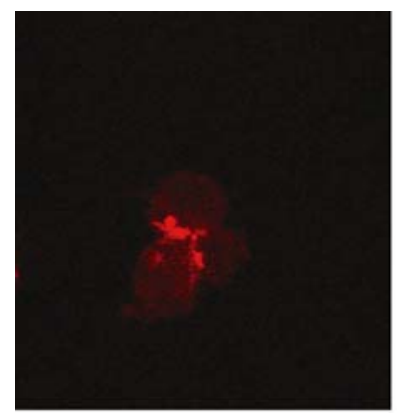

a

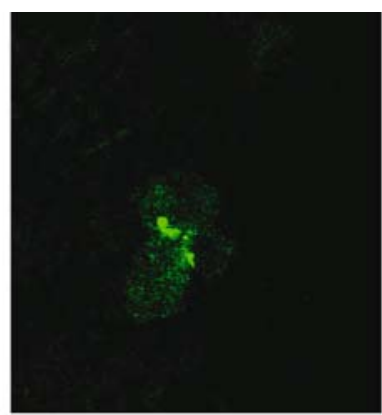

b

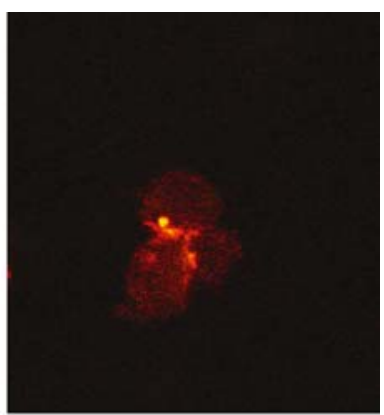

C

Fig. 8.35 Characterization of the Oval cell mediated from mesenchymal stem cell through coculture with hepatocyte by double staining using alpha-fetoprotein (AFP) and cytokeratin (CK) 19. a AFP - red b CK 19 - green $\mathrm{FP}$ and $\mathbf{c}$ CK 1

viruses that produce future unpredictable diseases from xenogeneic extracellular matrix may exist. If single-cell encapsulation by collagen containing signal transduction agents and ligands attracting specific cell adhesive receptors is systemized, commitment of stem cell differentiation and proliferation toward the designated target tissue will be achieved, and this may contribute to the future progress of stem cell-based implant. 

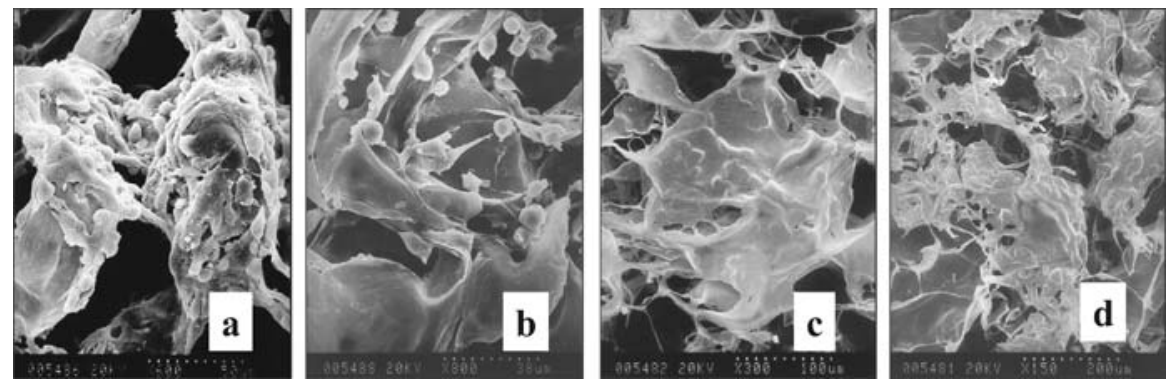

Fig. 8.36 SEM observation of oval cells seeded in porous collagen scaffold. a Oval cells in scaffold supplemented with cytokines at day 4, b Oval cells in scaffold supplemented with hormones at day 4, c Oval cells in scaffold supplemented with cytokines at day 7, d Oval cells in scaffold supplemented with hormones at day 7

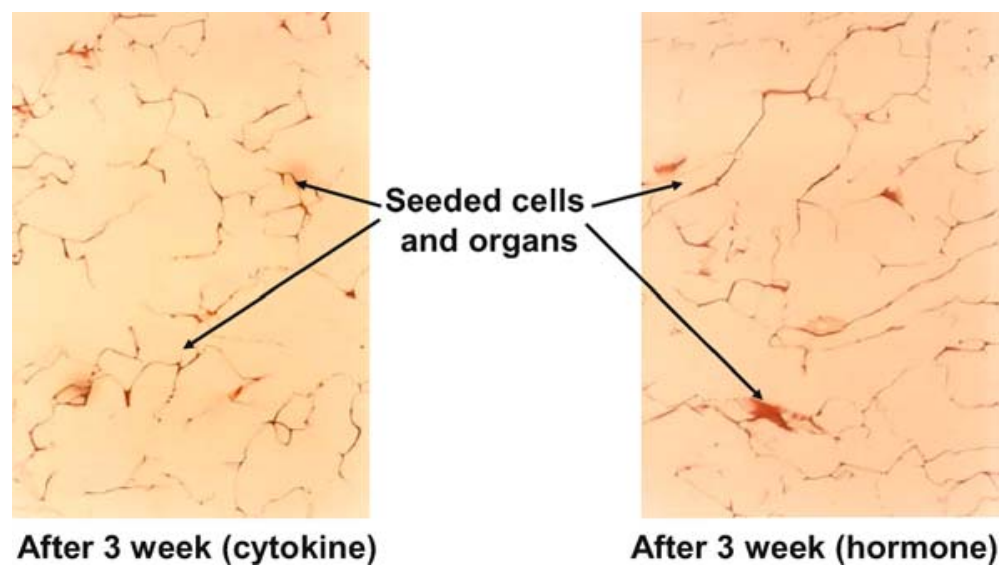

Fig. 8.37 Morphology of oval cells in scaffold. Masson \& Trichrome Staining
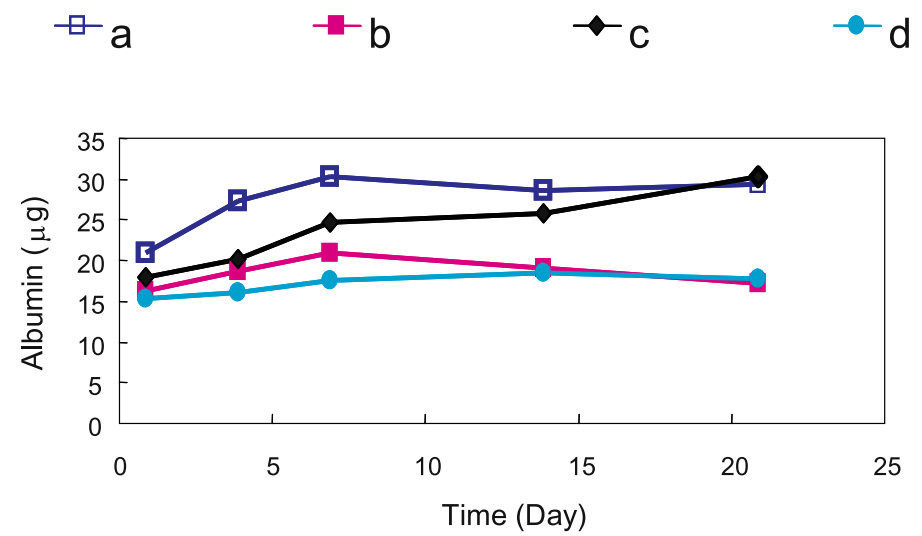

Fig. 8.38 Albumin secretion in scaffold. a Cultured with cytokines in scaffold, b Cultured with cytokines on tissue culture plate (TCP), c Cultured with hormones in scaffold, $\mathbf{d}$ Cultured with hormones on TCP 


\section{References}

1. Suh H (2000) Tissue Restoration, Tissue Engineering and Regenerative Medicine. Yonsei Medical Journal 41(6):681-684

2. Suh H (1998) Fundamental Concepts for Tissue Engineering. Biomaterials Research 2(1):1-7

3. Braybrook JH (1997) Biocompatibility assessment of medical devices and materials. John Wiley and Sons Ltd., West Sussex UK

4. Suh H (1998) Recent Advances in Biomaterials. Yonsei Medical Journal 39(2):87-96

5. Ruoslahti E, Engvall E (1994) Extracellular Matrix Components. Academic Press Inc., San Diego, CA,

6. Suh H, Suh S, Min B (1994) Anti-infection Treatment of a Transcutaneous Device by a Collagen-Rifampicine Composite. ASAIO Journal 40(3):406-411

7. Suh H (1999) Treatment of Collagen for Tissue Regenerative Scaffold. Biomedical Egineering Application and Basis Communication 11(4):167-173

8. Kim S-H, Lee J-H, Yun S-Y, Yoo J-S, Jun C-H, Chung K-Y, Suh H (2000) Reaction Monitoring of Succinylation of Collagen in Matrix-Assisted Desorption/Ionization Mass Spectrometry. Rapid Communication of Mass Spectrometry 14(12):2125-2128

9. Lee J-E, Park J-C, Hwang Y-S, Kim JK, Kim J-G, Suh H (2001) Characterization of UVirradiated Dense/Porous Collagen Membranes: Morphology, Degradation, and Mechanical Properties. Yonsei Medical Journal 42(2):172-179

10. Park S-N, Park J-C, Hae Ok Kim, Min Jung Song, Hwal Suh (2002) Characterization of Porous Collagen/Hyaluronic Acid caffold Modified by 1-ethyl-3(3dimethylaminopropyl)carbodiimide Cross-linking. Biomaterials 23(4):1205-1212

11. Lee J-E, Park J-C, Kim J-G, Suh H (2001) Preparation of Collagen Modified Hyaluronan Microparticles as Antibiotics Carrier. Yonsei Medical Journal 42(3):291-298

12. Suh H, Lee J-E (2002) Behavior of fibroblasts on a porous hyaluronic acid incorporated collagen matrix. Yonsei Medical Journal 43(2):193-202

13. Lee J-E, Park J-C, Lee KH, Oh SH, Suh H (2002) Laminin modified infection-preventing collagen membrane containing silver sulfadiazine-hyaluronan microparticles. Artificial Oragns 26(6):521-528

14. Lee J-E, Park J-C, Lee KH, Oh SH, Kim J-G, Suh H (2002) An infection-preventing bilayered collagen membrane containing antibiotic-loaded hyaluronan microparticles: physical and biological properties. Artificial Oragns 26(7):636-646

15. Park S-N, Lee HJ, Lee KH, Suh H (2003) Biological characterization of EDC-crosslinked collagen-hyaluronic acid matrix in dermal tissue restoration. Biomaterials 24(9):1631-1641

16. Park S-N, Kim JK, Suh H (2004) Evaluation of antibiotic-loaded collagen-hyaluronic acid matrix as a skin substitute. Biomaterials 25(17):3689-3698

17. Park S-N, Kim JH, Kim IH, Sul AR, Suh H (2006) Electrospun nanofibrous membrane for the engineering of cultured skin substitutes. Biomaterials Research 10(2):82-88 
18. Suh H, Lee C (1995) Biodegradable Ceramic-Collagen Composite Implanted in Rabbit Tibiae. ASAIO Journal 41(3):652-656

19. Suh H, Hwang Y-S, Song MJ, Lee WS, Han CD, Park J-C (2000) Behaviors of Osteoblasts-like Cell (MC3T3-E1) on Collagen Grafted Poly L-lactic Acid (PLLA) Membranes with Various Pore Sizes. Biomaterials Research 4(2):37-44

20. Park J-C, Han D-W, Suh H (2000) A Bone Replaceable Artificial Bone Substitute: Morphological and Physicochemical Characterization. Yonsei Medical Journal 41(4):468-476

21. Suh H, Hwang Y-S, Lee J-E, Han CD, Park J-C (2001) Behavior of Osteoblasts on type I Atelocollagen Grafted Ozone Oxidized Poly L-lactic Acid Membrane. Biomaterials 22(2):219230

22. Suh H, Park J-C, Han D-W, Lee DH, Han CD (2001) A Bone Replacable Artificial Bone Substittue: Cytotoxicity, Cell Adhesion, Proliferation, and Alkaline Phosphatase Activity. Artificial Organs 25(1):14-21

23. Suh H, Han D-W, Park J-C, Lee DH, Lee WS, Han CD (2001) A Bone Replaceable Artificial Bone Substitute: Osteoinduction by combining with Bone Inducing Agent. Artificial Organs 25(6):459-466

24. Kim H, Lee J-H, Suh H (2003) Interaction of Mesenchymal Stem Cells and Osteoblasts for in vitro Osteogenesis. Yonsei Medical Journal 44(2):187-197

25. Suh H, Song MJ, Ohata M, Kang Y-B, Tsutsumi S (2003) Ex Vivo Mechanical Evaluation of Carbonate Apatite-Collagen Grafted Porous PLLA Membrane in Rabbit Calvarial Bone. Tissue Engineering 9(4):635-643

26. Suh H, Hwang Y-S, Lee JE, Kim KT, Park JC, Park KD, Kim YH (1998) Type I Atelocollagen Grafting on Polyurethane Tube and its Mechanical Property. Biomaterials Research 2(4):158162

27. Suh H, Hwang Y-S, Kang Y-B, Nakai R, Tsutsumi S Park J-C (2000) Compliance of surface Modified Polyurethane Tubular Scaffold for Artificial Esophagus. Biomaterials Research 4(1):8-12

28. Park J-C, Hwang Y-S, Lee J-E, Park KD, Matsumura K, Hyon S-H, Suh H (2000) Type I Atelocollagen Grafting onto Ozone treated Polyurethane Films: Cell Attachment, Proliferation, and Collagen Synthesis. Journal of Biomedical Materials Research 52(4):669-677

29. Cha JM, Park S-N, Noh SH, Suh H (2006) Time-dependent modulation of alignment and differentiation of smooth muscle cells seeded on a porous substrate undergoing cyclic mechanical strain. Artificial Organs 30(4):250-258

30. Cha JM, Park S-N, Park G-O, Kim JG, Suh H (2006) Construction of functional soft tissues from premodulated smooth muscle cells using a bioreactor system. Artificial Organs 30(9):704-707

31. Suh H, Park S-N, Kim JH (2003) Evaluation of tissue adhesion preventive surface modified natural and synthetic polymeric materials. Materials Science Forum 426-432(2003):32553260

32. Park SN, Jang HJ, Choi YS, Cha JM, Son SY, Han SH, Kim JH, Lee WJ, Suh H (2007) Preparation and characterization of biodegradable anti-adhesive membrane for peritoneal wound healing. Journal of Materials Science: Materials in Medicine 18:475-482

33. Suh H, Song MJ, Park YN (2003) Behaviors of isolated rat oval cells in porous collagen scaffold. Tissue Engineering 9(3):411-420 